\title{
MCQ-Balance: A method to monitor patients with balance disorders and improve clinical interpretation of posturography
}

\author{
Juan De la Torre ${ }^{\text {Corresp., } 1,2}$, Javier Marin ${ }^{1,3}$, Marco Polo ${ }^{4}$, Eva M. Gómez-Trullén ${ }^{1,5}$, Jose J. Marin ${ }^{1,3}$ \\ 1 IDERGO (Research and Development in Ergonomics) Research Group, I3A (Aragon Institute of Engineering Research), Zaragoza, Spain \\ 2 Department of Biomedical Engineering, Universidad de Zaragoza, Zaragoza, Spain \\ 3 Department of Design and Manufacturing Engineering, Universidad de Zaragoza, Zaragoza, Spain \\ 4 MD Physical Medicine and Rehabilitation, Hospital of Alcañiz, Teruel, Spain \\ 5 Department of Physical Medicine and Rehabilitation and Nursing, Health Sciences Faculty, Universidad de Zaragoza, Zaragoza, Spain \\ Corresponding Author: Juan De la Torre \\ Email address: 627471@unizar.es
}

Background: An estimated $20 \%$ to $30 \%$ of the global population has suffered a vertiginous episode. Among them, $20 \%$ do not receive a clear diagnosis. Improved methods, indicators and metrics are necessary to assess the sensory systems related to balance, especially when patients are undergoing treatment for vertiginous episodes. Patients with balance disorders should be monitored for changes at the individual level to gather objective information. In this study, we evaluate the use of the MCQBalance (Measure, Classify and Qualify) assessment for examining a patient's balance progression using tests to measure static balance control and dynamic postural balance with a stabilometric platform.

Materials and Methods: The MCQ-Balance assessment comprises three stages: i) measuring the progression of each variable between two separate and consecutive days (called sessions) using the Magnitude-Based Decision analysis; ii) classifying the progression of the patient's balance with a score; and iii) qualifying the progression of the patient's balance from the resulting scores using a set of rules. This method was applied to 42 patients with balance disorders of peripheral or central origin characterised by vertigo as the cardinal symptom. Balance progression was measured using the MCQBalance assessment over the course of three months, and these results were compared with the assessment of a clinical expert.

Results: The MCQ-Balance assessment showed an accuracy of $83.4 \%$ and a Cohen's Kappa coefficient of 0.752 compared to the assessment of a clinical expert.

Conclusion: The MCQ-Balance assessment facilitates the monitoring of patient balance and provides objective information that has the potential to improve medical decision making and the adjustment of individual treatment. . 


\section{MCQ-Balance: A method to monitor patients with}

2 balance disorders and improve clinical interpretation

3 of posturography

4

5 Juan de la Torre ${ }^{1,2}$, Javier Marin ${ }^{1,3}$, Marco Polo 4 , Eva M. Gómez ${ }^{1,5}$ and Jose J. Marin ${ }^{1,3}$

$7 \quad{ }^{1}$ IDERGO (Research and Development in Ergonomics) Research Group, I3A (Aragon Institute of

8 Engineering Research), Zaragoza, Spain.

$9 \quad 2$ Department of Biomedical Engineering, University of Zaragoza, Zaragoza, Spain.

$10{ }^{3}$ Department of Design and Manufacturing Engineering, University of Zaragoza, Zaragoza, Spain

$11{ }^{4}$ MD Physical Medicine and Rehabilitation, Hospital of Alcañiz, Teruel, Spain

$12{ }^{5}$ Department of Physical Medicine and Rehabilitation and Nursing, Health Sciences Faculty,

13 University of Zaragoza, Zaragoza, Spain.

14

15

16

17

Corresponding Author:

19 Juan de la Torre ${ }^{1,2}$

20 IDERGO Research Group, I3A, University of Zaragoza, Zaragoza, Spain.

21 Email address:627471@unizar.es 


\section{Abstract}

24 Background: An estimated $20 \%$ to $30 \%$ of the global population has suffered a vertiginous

25

26

27

28

29

30

31

32

33

34

35

36

37

38

39

40

41

42

43

44

45

46

47

48

49

50

51

52

53

54

55

56

57

58

59

60

61

62

episode. Among them, 20\% do not receive a clear diagnosis. Improved methods, indicators and metrics are necessary to assess the sensory systems related to balance, especially when patients are undergoing treatment for vertiginous episodes. Patients with balance disorders should be monitored for changes at the individual level to gather objective information. In this study, we evaluate the use of the MCQ-Balance (Measure, Classify and Qualify) assessment for examining a patient's balance progression using tests to measure static balance control and dynamic postural balance with a stabilometric platform.

Materials and Methods: The MCQ-Balance assessment comprises three stages: i) measuring the progression of each variable between two separate and consecutive days (called sessions) using the Magnitude-Based Decision analysis; ii) classifying the progression of the patient's balance with a score; and iii) qualifying the progression of the patient's balance from the resulting scores using a set of rules. This method was applied to 42 patients with balance disorders of peripheral or central origin characterised by vertigo as the cardinal symptom. Balance progression was measured using the MCQ-Balance assessment over the course of three months, and these results were compared with the assessment of a clinical expert.

Results: The MCQ-Balance assessment showed an accuracy of $83.4 \%$ and a Cohen's Kappa coefficient of 0.752 compared to the assessment of a clinical expert.

Conclusion: The MCQ-Balance assessment facilitates the monitoring of patient balance and provides objective information that has the potential to improve medical decision making and the adjustment of individual treatment.

Keywords: Vertigo, patient-level analysis, monitoring, balance sensory systems, stabilometric platform, methodology, interpretable score, personalized medicine.

\section{Introduction}

Vertigo is an illusion of movement, either of the external world revolving around the individual or of the individual revolving in space (Medical Subject Headings (MeSH), 2020). It is the cardinal symptom of balance, which leads to a significant reduction in the quality of life and an increase in disability, anxiety and depression (Neuhauser, 2016). There is a high prevalence of balance disorders among elderly people in developed countries (Penger, Strobl \& Grill, 2017; Rubenstein, Josephson, 2002). In combination with a gradual increase in the ageing index of the population (Vaupel, Loichinger, 2006; Muir et al., 2013), it has resulted in an increase in the risk of falls of elderly people (Aftab, Robert \& Wieber, 2016; Khalaj et al., 2014). Globally, approximately 20 to $30 \%$ of the population has a vertiginous episode of various origins and severity over a lifetime (da Costa Barbosa, Vieira, 2017; Lin et al., 2008; Wolf et al., 1996; Tinetti, 2003). Moreover, $20 \%$ of them do not receive a clear diagnosis (Swanenburg et al., 2008).

Peer) reviewing PDF | (2020:07:51331:2:1:NEW 8 Jan 2021) 
63 Vertigo is most often caused by dysfunction resulting from a peripheral or central lesion (Stanton

$64 \mathrm{M}, 2020 \mathrm{Apr} 28$ ); therefore, depending on the origin, it can be classified as vertigo of peripheral 65 or central origin (Wipperman, 2014; Baumgartner B, 2019 Jun 3; Strupp, Dieterich \& Brandt, 66 2013). Vertigo can also have a cervical origin in cases where the central nervous system is 67 unaffected (except spinal cord syndrome), with a demonstrated relationship between cervicalgia 68 and vertigo (Dieterich, Eckhardt-Henn, 2004; Reiley et al., 2017). Vertigo of cervical origin is 69 identified most frequently in rehabilitation consultations, occurring most often in patients 70 between the ages of 30 and 50 (Jull, 2004; Solomon, 2000).

71 To analyse the causes of vertigo, the degree of alteration must be measured in isolation or in 72 combination of each balance sensory system (BSS), including the vestibular (VS), visual (ES;

73

74

75

76

77 78

79

80

81

82

83

84

85

86

87

88

89

90

91

92

93

94

95

96

97

98

99

100

101

102 eye-sight), and proprioceptive (PS) systems. A vertiginous episode or trauma can affect these systems to a greater or lesser extent, and consequently, the patient's balance (Hanes, McCollum, 2006; Shumway-Cook, A. et al., 2001). It is therefore necessary to have methods or indicators to determine how the BSS progresses and to standardize the initial evaluation of patients' balance and its progression, especially during the treatment of a balance disorder (Patrícia Paludette, Fabrício Santana da \& Carlos Bolli, 2015).

When it is challenging to establish a clear pathology related to any of the BSSs, or when multiple origins of the condition are found, the clinical diagnosis becomes complicated (Derebery, 2000), and additional measures and tests are required to provide important information to the clinician (Hickey et al., 1990; Martínez Carrasco, 2016; Vellas et al., 1997).

As an alternative or complement to the functional tests, using a stabilometric platform, posturography allows movements of the centre of pressure (COP) in the standing position to be measured. Stabilometric platforms can assess static balance control and dynamic postural balance through different variables and application methods (Ito et al., 2020; Choi, Lee, 2020). It constitutes a functional assessment with medical-legal validity that provides objective information regarding balance disorders in clinical practice (De la Torre et al., 2017; Dounskaia, Peterson \& Bruhns, 2018; Lin et al., 2008). Although posturography is a validated assessment, difficulties are encountered with regard to discerning the origin caused by the imbalance pattern. This is because, although sensory analyses suggest a proprioceptive-visual-vestibular pattern, this is not always accurate (El-Kashlan et al., 1998; Stewart et al., 1999; Timothy C. Hain, May 5 , 2019). Related to the above, although the clinical results from traditional posturography are useful, they are insufficient in certain cases, requiring smarter devices (Allum et al., 2002; Di Fabio, 1996).

Posturography devices can provide information on patients' balance that is useful for clinical decision-making, as a functional assessment value, measuring data related to the patients' balance; however, in order for such devices to be practical, they must be easy for clinicians to use without consulting external experts (Visser et al., 2008). Although several balance assessment tests have been applied through a stabilometric platform (Karlsson, Frykberg, 2000), their resulting scores are sometimes complex and difficult to interpret (Peterson et al., 2003). To this end, subjective scoring lacks standardization and can be 
103

104

105

106

107

108

109

110

111

112

113

114

115

116

117

118

119

120

121

122

123

124

125

126

127 difficult to interpret, thus making difficult classify the patient balance status, which resulting in difficulties diagnosing balance disorders and identifying the BSS from which the imbalance pattern originates (Jacobs et al., 2006; Visser et al., 2008; Saxena, Prabhakar, 2013). Posturography reports should involve easily understandable, non-technical language, qualifying the patient's balance status in an understandable way for clinicians (Von Lubitz,

Wickramasinghe, 2006; Visser et al., 2008). Likewise, both validation and standardization of the protocols for reproducibility and a possible comparison with similar studies are required (Visser et al., 2008).

In rehabilitation, it is critical to measure the progression of a patient's balance between two separate sessions in order to objectively characterize the response to treatments (Hamburg, Collins, 2010); this helps determine whether relevant changes have occurred in the patient at the individual level, thus informing future treatment decision making (Visser et al., 2008; Hopkins, Will G., 2017). Regarding this, we can highlight the proposal of (Hopkins, Will G., 2017) to assess the change between two measurements in an individual through the magnitude-based decision (MBD) method (Hopkins, William G., 2019), which is used in this work.

The development of the MCQ-Balance assessment method was motivated by these issues, in relation to the necessity of providing objective, easily-interpretable information about patients' balance that specifies the origin of the pathology. Using a stabilometric platform, this method detects relevant changes between two consecutive balance tests (monitor) in patients with balance disorders, providing objective information about the origin of the imbalance. The MCQ-Balance assessment comprises three separate stages in which the progression of a patient's balance is measured, then classified, and finally qualified. In this study, the MCQ-Balance assessment was applied to balance disorder patients with vertigo as the cardinal symptom. Subsequently, the results obtained were compared with the evaluation of a specialist clinician. 


\section{Materials \& Methods}

129

130

131

132

133

134

135

136

137

138

139

140

141

142

143

144

145

146

147

148

149

150

151

152

153

154

155

156

157

158

159

160

161

162

163

164

165

166

167

\section{Participants}

A total of 42 patients with balance disorders characterised by vertigo (of peripheral or central origin) as the cardinal symptom were monitored via balance tests with a stabilometric platform. The patients were referred by the Primary Care, Otorhinolaryngology and Neurology Services of the Alcañiz Hospital (Teruel, Spain) after being diagnosed with a balance disorder. The methods for determining the deficit, varied according to the service where the diagnosis was made: i) in Primary Care, medical history was considered; ii) in Otorhinolaryngology, in addition to the medical history, magnetic resonance imaging, videonystagmography, and tests such as the DixHallpike manoeuvre were used; and iii) in Neurology, in addition to medical history and magnetic resonance imaging, computerized axial tomography and neurophysiology tests, were used. Table 1 presents the main diagnoses of the patients with respect to peripheral or central deficits. Table 2 shows general and anthropometric characteristics of the patient population. The study included 27 females (64\%) and 15 males (36\%), and there were no statistically significant differences in any baseline characteristics according to sex (Yin et al., 2009).

\section{Table 1 about here}

\section{Table 2 about here}

From these diagnostic services, patients from the Teruel region (Spain) were referred to the Physical Medicine and Rehabilitation Service (PM\&R) of the Alcañiz Hospital, having been identified with vertigo as the cardinal symptom. A doctor (clinician 1) of the PM\&R service then evaluated the patients, considering i) their medical history and physical examination, ii) previous diagnosis and iii) the results of the functional balance assessments carried out, such as the Unterberger test (Bartual, Pérez, 1998; Hickey et al., 1990), up and go test (Martínez Carrasco, 2016; Shumway-Cook, Anne, Brauer \& Woollacott, 2000), and unipodal support test (Vellas et al., 1997).

The selected patients met the following inclusion criteria: (i) between 35 and 70 years old and (ii) having suffered a vertiginous episode of peripheral or central origin in the last year. The following were the exclusion criteria, which were based on (Degani, Leonard \& Danna-dosSantos, 2017; Hanes, McCollum, 2006; Swanenburg et al., 2007; Tsukamoto et al., 2015) and were applied in other research (De la Torre et al., 2020): (i) presented acute osteomuscular pathology in the lower limbs or lumbar spine, which may alter the outcome of the stabilometric platform, (ii) presented any amputation in the lower limbs, or (iii) presented oncological pathology or was in active treatment with chemotherapy, radiotherapy, or hormonal therapy. The present study was approved by the Research Ethics Committee of the Community of Aragon (CEICA) (January 16, 2019) and complied the ethical standards of the Declaration of Helsinki (General Assembly of the World Medical Association, 2014). 
168 Prior to the start of the tests, the participants signed a consent form sheet that involved accepting

169

170

171

172

173

174

175

176

177

178

179

180

181

182

183

184

185

186

187

188

189

190

191

192

193

194

195

196

197

198

199

200

201

202

203

204

205

206

207

the tests and understanding the purpose of them. The participants in this study has given written informed consent to publish these case details.

The choice of 42 patients was based on the following formula for sample size calculation involving qualitative variables (Charan, Biswas, 2013):

$$
N=\frac{\left(Z_{1-\alpha / 2}\right)^{2} p(1-p)}{d^{2}}
$$

Here, $\mathrm{Z}_{1-\alpha / 2}$ is the standard normal variate with $\mathrm{p}_{\mathrm{v}}<0.05$ (type I error); $\mathrm{p}$ is the expected proportion of the research goal in population; and $d$ is the absolute error or precision, as determined by the researcher. We selected a $Z_{1-\alpha / 2}$ value of 1.96 (standard, given that $p_{y}$ values are considered statistically significant below 0.05 ), a p-value of 0.7 (based on initial criteria that showed an accuracy of $>70 \%$, as shown in the statistical analysis section), and a d-value of 0.15 . The resulting N-value was 39.85 .

\section{Instrumentation}

The device used was the stabilometric platform MoveHuman-Dyna UZ, which was designed and manufactured by the IDERGO (Research and Development in Ergonomics, University of Zaragoza, Spain) research group (see Figure 1). It is a static posturography device designed for research, which comprises four load cells and a lightweight aluminium structure, whose dimensions and characteristics are detailed in the study of De la Torre et al. (2017). The findings of this device can be replicated in a straightforward manner by other researchers, which enhances the applicability of this study. The acquisition and processing of the platform data, as well as the format and method of exporting them, have been carried out according to the procedure used by De la Torre et al. (2017).

Likewise, in accordance with the aforementioned study, the stabilometric platform 'meets the standards established by the International Society for Posture and Gait Research (ISPGR) for its clinical application' (Scoppa et al., 2013) in relation to various parameters, such as accuracy, precision, linearity, dimensions, resolution, sampling, and so on. The precision parameters (accuracy, precision, linearity, dimensions and resolution) were obtained through a reliability experiment in which the metrological characteristics of the platform were tested with a gold standard force platform, as well as the error of measurement (De la Torre et al., 2017).

Processing the force data in function of the cells' position means we can calculate the real-time position of the trajectory that describes the position of the COP by applying the appropriate formula (López, Calidonio, 2009; Ma et al., 2016). The stabilometric platform has been used in several research projects with patients in different hospitals since 2018, both public (hospital Miguel Servet and university hospital Lozano Blesa (Zaragoza, Spain)) and private (hospital MAZ (Zaragoza, Spain)); all the research projects have been approved by the CEICA

Committee. In addition, the characteristics of the platform and its portability make it suitable for clinical use where, for example, the medical office space is limited (Scoppa et al., 2013; De la Torre et al., 2017).

Peer) reviewing PDF | (2020:07:51331:2:1:NEW 8 Jan 2021) 


\section{Protocol}

211 Patients were evaluated by clinician 1 on two different days (sessions) spaced three months apart

212 (first session: pre-session; second session: post-session). After the pre-session, clinician 1

213 prescribed the rehabilitation treatment according to the specific balance disorder of each patient.

214 Patients with vertigo of peripheral or central origin performed vestibular rehabilitation exercises

215 (Boomsaad, Telian \& Patil, 2017). For patients with a specific diagnosis of benign paroxysmal

216 peripheral vertigo (BPPV), the Epley manoeuvre was performed in addition to vestibular

217 rehabilitation exercises (Orejas et al., 2020; Hansson, Persson \& Malmström, 2013).

218

219

220

221

222

223

224

225

226

227

228

229

230

231

232

233

234

235

236

237

238

239

240

241

242

243

244

245

246

247

After the evaluation by clinician 1, in each session (pre and post), the patients conducted a set of balance evaluation tests with a stabilometric platform (three months apart between the pre- and post-session). The tests were performed by the PM\&R of the Alcañiz Hospital between February and July in 2019. The fieldwork was performed by a team of a clinician (clinician 2), a nurse, and a technician in the same hospital.

The static and dynamic balance were both assessed with a set of tests previously applied in other studies (De la Torre, Marin et al., 2020; De la Torre et al., 2017).

Static balance control was assessed with a test based on the Romberg test and the Modified Clinical Test of Sensory Interaction in Balance (CTSIB-M). In the test patients must maintain their COP within the support base throughout the assessment period - $40 \mathrm{sec}$. (De la Torre et al., 2017). Static balance control was assessed in four different conditions, examined consecutively: (1) rigid surface with eyes open (RSEO), (2) rigid surface with eyes closed (RSEC), (3) soft surface with eyes open (SSEO), and (4) soft surface with eyes closed (SSEC).

On the other hand, the dynamic postural balance, which is vital for motor control, was assessed measuring the limits of stability (LOS) that a patient is able to reach and with it, the management capacity of COP $(\mathrm{Ku}, \mathrm{Abu}$ Osman \& Wan Abas, 2016). The inclusion of the LOS, complementary to the assessment of the static balance control, provides additional value to the balance assessment protocol (Lin et al., 2008; Tesio et al., 2013; Salehi et al., 2010)

The specific protocol applied in the tests: the position of the body, arms and feet during the test (De la Torre et al., 2017), environmental conditions (e.g. noise, space, etc.) and the additional instrumentation used as a foam rubber for soft surface or instruments for anthropometric data collection, is the same that (De la Torre et al., 2020) used for this stabilometric platform (Figure 1). This protocol fulfils certain clinical conditions (Swanenburg et al., 2008; Hoving et al., 2005; Benvenuti et al., 1999; Doyle, Newton \& Burnett, 2005); it must be fast and should not require multiple repetitions to issue a definite, consistent result (Swanenburg et al., 2008).

At the start of the tests, clinician 2 provided patients with instructions on how to perform the tests, according to similar studies (De la Torre et al., 2020; De la Torre et al., 2017). The patients were instructed on how to place their feet on the platform according to the mark placed in the stabilometric platform shown in figure 1 (a). The patients had to be in a standing position, with the arms extended and close to the body. The patients were instructed to keep as still as possible in the

Peer) reviewing PDF | (2020:07:51331:2:1:NEW 8 Jan 2021) 
248 static tests; in the LOS, they were instructed to, using only the movement of the ankles without 249 lifting the feet, follow a moving target LOS as explained by (De la Torre et al., 2017). Clinician 2 250 also provided instructions on how to stimulate abdominal toning, since this has an influence on 251 stability and balance (Ayllón, Fernández, 2006). Patients completed a practice run of each test so 252 that clinician 2 could verify that they understood the procedure, assumed the correct posture, and 253 executed the tests correctly. This also gave the patients the opportunity to get used to the platform 254 and environment, which are considered relevant factors in some balance studies (Taylor et al., 255 2015).

256

257

\section{Variables}

258 The variables selected for the present study were those determined by De la Torre et al. (2017).

259 to be more significant in balance assessment studies, which details, and method of obtaining are

260 also explained in the same study. The variables selected for the assessment of the static and 261 dynamic balance were the range of displacement in the anteroposterior and mediolateral 262 directions in $\mathrm{mm}$, area in $\mathrm{cm}^{2}$ (surface area covered by the trajectory of the COP), average speed 263 of the COP in $\mathrm{mm} / \mathrm{s}$, and RMS position in $\mathrm{mm}$. Additionally, in the LOS test, two more variables 264 were assessed: the COP limits in mm (maximum displacement reached along each axis of the 265 octagon radii), and the "success" variable in percentage (quantification of the management and 266 coordination of the COP along each axis of the octagon radii), both defined in previous studies 267 (De la Torre et al., 2020; De la Torre et al., 2017).

268

\section{MCQ-Balance assessment method}

Figure 2 presents the application outline of the MCQ-Balance assessment, which consists of three stages in which the progression of a patient's balance is Measured (M), Classified (C), and Qualified (Q). The method input is the variables provided by the set of balance tests in two temporal points, that is, the values of the variables in the pre-session and post-session. The variables are analysed individually until stage two, where they are grouped at the test level until the end of the assessment. The application outline shows the inputs and outputs of each stage, as well as the processes (P1-P5) applied to them. It also includes the type of information that is handled and the interpretative changes during the process.

\section{Figure 2 about here}

\section{Stage 1: Measure}

The first stage of the method involves measuring the progression of each variable of the balance tests set by detecting relevant changes between two measures of each variable recorded at different temporal points (e.g., a measure of 26.4 for one session and 27.2 for another session). For this purpose, the process (P1) used in this stage is the statistical method MBD, as described in the Spreadsheet for Monitoring an Individual's Changes (Hopkins, Will G., 2017) (formerly 
287

288

289

290

291

292

293

294

295

296

297

298

299

300

301

302

303

304

305

306

307

308

309

310

311

312

313

314

315

316

317

318

319

320

321

322

323

324

325

known as magnitude-based inferences) (Hopkins, William G., 2019). According to the MBD method, some inputs are required for each analysed variable:

- Xdif: difference between the measures taken in two temporal points: pre-value (presession) and post-value (post-session) (Equation 1).

$$
X \text { dif }=X_{\text {post }}-X_{\text {pre }}
$$

- MBD threshold: for this method, a threshold (numerical value) must be defined from which a change is considered relevant. In our case, we selected the minimal detectable change (MDC) (Equation 2). The implications of this election are explained in the discussion section.

$$
M D C=1.96 \sqrt{2} \text { SEM } ; S E M=S D p o o l \sqrt{1-I C C}
$$

Where the standard deviation (SDpool) is the pooled average between the standard deviation of the test and retest, ICC is the intraclass correlation coefficient (specifically, the calculated coefficient was ICC3, k (similar to ICC2.1) (Ruhe, Fejer \& Walker, 2010); the statistical software used for the ICC calculations was the IBM SPSS statistics (IBM Corp, 2017) and the ICC results were classified according to (Cicchetti, 1994), who provided the following intervals to characterize the ICC inter-rater agreement measures; and SEM is the standard error of measurement. Following the exposed calculation procedure, ICC, SEM and MDC values were obtained in a previous test-retest study (De la Torre et al., 2020).

- Short-term typical error (STTE): this represents the error/deviation in the subject's repeated measurements in a short period for a sample of measurements instead of just one measurement per session, without any substantial change between them (as an intervention, for a long time between measurements, etc.) As proposed by (Hopkins, Will G., 2000; Hopkins, Will G., 2017), this input was obtained with a previous short-term reliability study of the balance test set; similar study to the calculation of variables for the MDC (De la Torre et al., 2020).

To detect whether the change is relevant between two recorded measures, clinical MBD is followed (Hopkins, Will G., Batterham, 2016). This allows us to determine whether the detected progression is positive (beneficial), negative (harmful) or inconclusive.

First, with the value and sign (positive or negative) of Xdif, we determine the tendency of the change towards a positive or negative progression. In the MCQ-Balance assessment method, we follow the following criteria based on (De la Torre et al., 2020): for the static balance group, a positive progression is considered if Xdif has a negative sign, and for the dynamic balance group, a positive progression is considered if Xdif has a positive sign.

Subsequently, following the calculation method set forth by (Hopkins, Will G., 2017), the probability of change ( $\mathrm{PoC}$ in \%) is obtained, which can be defined as the probability that the difference between the two values is relevant. This probability corresponds to the percentage of the confidence interval of the difference (calculated using the Xdif and STTE) that is outside of the range (+MDC, $-\mathrm{MDC})$. 
326 Once the PoC is calculated in the method, criteria must be established to consider a positive,

327

328

329

330

331

332

333

334

335

336

337

338

339

340

341

342

343

344

345

346

347

348

349

350

351

352

353

354

355

356

357

358

359

360

negative, or null (unclear) progression of each variable. In a case study following the clinical MBD, a positive $\mathrm{PoC}$ that is greater than or equal to $25 \%$ corresponds to a relevant positive change, whereas a negative $\mathrm{PoC}$ that is greater than or equal to $5 \%$ corresponds to a relevant negative change in the patient. In contrast, if the positive $\mathrm{PoC}$ is less than $25 \%$ or the negative $\mathrm{PoC}$ is less than $5 \%$, the change is considered 'unclear'. The asymmetry between the two intervals is because, in 'Clinical MBD the effects have an unacceptable risk of harm' (Hopkins, Will G., Batterham, 2016).

\section{Stage 2: Classify}

The second stage of the method consists of classifying the progression of each patient using a scoring. First, a specific score for each variable is calculated individually. Subsequently, from the scores of each variable, a score is obtained for each test. Finally, the test score is simplified, and a homogenised score (a discrete variable with the values $-2,-1,0,+1$ and +2 ) is calculated for each of them, making it possible to compare the tests with different numbers of variables. To determine the specific score for each variable ( $\operatorname{Score}_{v_{m}}$ or the score of the variable $\mathrm{m}$ ), Equation 3 (P2) was used:

$$
\text { Score }_{v_{m}}=P o C+C Q
$$

- PoC: Probability of change for one unit (calculated in 2.4).

- CQ: Quantification of the change that represents the dimensionless difference between the pre- and post-sessions (for one unit) calculated using Equation 4, in which Xdif is divided by the maximum value of the pre- or post-session. If Xdif is very large (tending to infinity), CQ approaches 1 :

$$
\text { - } \quad C Q=\frac{X \text { dif }}{\operatorname{Max}(X \text { post; } X \text { pre })}
$$

Considering Equations 2 and 3, the range of Score $_{v_{m}}$ is 0 to +2 (positive progression) or -2 to 0 (negative progression). The score per variable is a continuous quantitative variable.

As mentioned above, the present study included five tests (four variants of the Romberg test and the LOS test); therefore, through a calculation based on the variable scores (P3), we obtained five values referred to as Score Test $_{n}$. In the static balance tests, four situations were considered in which five variables were obtained in each one. In the LOS test, 20 variables were obtained. Equation 5 shows how to calculate the value for Score $_{\text {Test }}$.

$$
\text { Score }_{\text {Test }}=\Sigma_{m}^{N_{\text {test }} \text { Score }_{v_{m}}}
$$

where $\mathrm{N}_{\text {test }}$ is the number of variables per test. Likewise, in Equations 6 and 7, the maximum and minimum scores that the Score $_{\text {Test }_{n}}$ can reach are shown.

$$
\text { MaxScore }_{\text {Test }_{n}}=2 N_{\text {test }}
$$




$$
\text { MinScore }_{\text {Test }_{n}}=(-2) N_{\text {test }}
$$

362 For the static balance tests, the maximum and minimum scores were +10 and -10 , respectively.

363

364

365

366

367

368

369

370

371

372

373

374

375

376

377

378

379

380

381

382

383

384

385

386

387

388

389

390

391

392

393

394

395

396

397

398

For the LOS test, the maximum and minimum scores were +40 and -40 , respectively.

Due to the different ranges of scores for each test, it is necessary to perform a classification that homogenises and simplifies the scores independently of the number of variables selected in the previous phases. For this, a process (P4) is conducted in which the global scores are transformed into a discrete quantitative variable through categorisation (González et al., 2014), establishing a classification of five scores between -2 and +2 . The proposed intervals are shown in brackets, which were defined based on statistical criteria, the processing and analysis of the data and the view of the clinician 2 involved in the present study:

- -2 : high negative progression from Test ${ }_{n}\left(30 \%\right.$ MinScore $_{\text {Test }_{n}}>$ Score $\left._{\text {Test }_{n}}\right)$.

- -1: negative progression from Test ${ }_{n}\left(30 \%\right.$ MinScore $_{\text {Test }_{n}} \leq$ Score $_{\text {Test }_{n}}<10 \%$ Min Score $\left._{\text {Test }_{n}}\right)$.

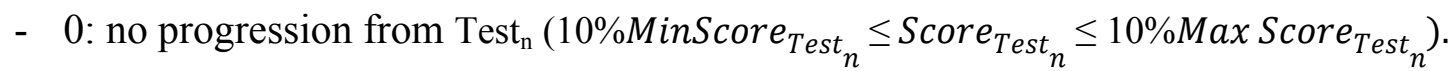

- +1: positive progression from Test $_{n}\left(10 \%\right.$ MaxScore $_{\text {Test }_{n}}<$ Score $_{\text {Test }_{n}} \leq 30 \%$ Max $_{\text {Score }}$ Test $\left._{n}\right)$.

- $\quad+2$ : high positive progression from Test $_{\mathrm{n}}\left(30 \%\right.$ MaxScore $_{\text {Test }_{n}}<$ Score $\left._{\text {Test }_{n}}\right)$.

\section{Stage 3: Qualify}

The third and final stage involves using established criteria to qualify the progression based on the resulting scores from stage two. For this purpose, rules based on a decision tree model (see Figure 3) are proposed to qualify the progression of the balance in a patient and the influence of the involved BSS.

As mentioned above, balance is supported by the visual, proprioceptive and vestibular systems. Consequently, in the set of tests presented in Section 2.2, the patient was deprived successively of one or more BSS:

- RSEO: no BSS altered.

- RSEC: ES altered. The balance depends on the VS and PS.

- SSEO: PS altered. The balance depends on the VS and ES.

- SSEC: ES and PS altered. The balance depends only on the VS.

- LOS: no BSS altered. Unique dynamic postural balance test.

Thus, five rules are proposed that lead to their corresponding conclusions (see 'Conclusions for each situation assessed' in Figure 3). The clinicians of the present study developed these conclusions. In addition, the rules are divided into two groups: those directly obtained (1, 2, and 3 ) and those obtained in combination (4 and 5).

Rules 1 and 2 allow to obtain a global assessment of the progression of the static balance control and the dynamic postural balance of a patient from the RSEO and LOS tests, respectively. Rule 3 allows to obtain an assessment of the influence of the VS on the progression of a patient's balance, analysing the SSEC test. Rules 4 and 5 assess the influence of the ES and PS, respectively, on the progression of a patient's balance. These rules result from the combination 
399

400

401

402

403

404

405

406

407

408

409

410

411

412

413

414

415

416

417

418

419

420

421

422

423

424

425

426

427

428

429

430

431

432

433

434

435

436

437

438

of SSEC with SSEO (Rule 4) and with RSEC (Rule 5), first analysing the SSEC test and then the corresponding one according to the rule.

\section{Figure 3 about here}

\section{Comparison between the MCQ-Balance assessment and clinician judgment}

To analyse the application of the MCQ-Balance assessment, the patient results provided by this method have been compared with the assessment of a clinical expert (clinician 3).

The pre- and post-session data collected by clinician 1 (history and physical examination, diagnosis and functional assessment tests) were assessed by clinician 3 at the end of the field work, which allowed an assessment of the balance progression of each of the 42 patients. To avoid the results being influenced or contaminated by the interaction between the clinicians, there was no contact between them during the research.

The assessment of clinician 3 established three possible categories to evaluate patient progression: positive, null or negative progression (represented by “+”, "="” and "_“", respectively). Regarding the MCQ-Balance assessment, the RSEO variant of the static balance test and LOS test was chosen to make the comparison. This decision was motivated by the fact that, in the RSEO test, the subject has all the BSSs necessary to maintain stability, which corresponds to the standard situation where all BSSs are intact; it is a more favourable test and more consistent with the performance of daily living activities. In addition, in the LOS test (where the capacity or stability limits of patients are measured), the patient is also not deprived of any BSS; therefore, both tests are performed under the same conditions, which we consider in favour of the assessment used in this study (between the results of the pre-treatment and posttreatment session).

Likewise, and since clinician 3 could only establish a classification in three categories, the MCQBalance assessment scores have been simplified to a positive ( +2 and +1 simplified to ' + '), null ( 0 simplified to ' $=$ ') and negative ( -2 and -1 simplified to ' $-')$ progression in order to properly conduct the comparison.

\section{Statistical analysis}

We used the statistical software IBM SPSS statistics Version 25 (IBM Corp, 2017) for the statistical analysis of the data. To make the comparison between the MCQ-Balance assessment results and the assessment of clinician 3, the Cohen's Kappa statistical coefficient ( $\kappa)$ was chosen (Cantor, 1996), which is used to measure inter-rater reliability for qualitative (categorical) items. Likewise, the confusion matrix was calculated to obtain the accuracy and percentage of false negatives.

Regarding the results of the comparison, it would be reasonable to obtain a Cohen's Kappa coefficient of a moderate or higher category (index above 0.4 ), as well as an accuracy of more than $70 \%$ to minimize the number of false negatives. 


\section{Results}

440 The results of the statistical analysis of the comparison between the MCQ-Balance assessment

441 and the evaluation of clinician 3 are presented below.

442

443 Stage 1

444 Regarding phase 1, the average PoC is presented for each patient's tests (see Table 3 ). The

445 motivation for the choice of PoC is the main output of phase 1 and, therefore, the most

446 representative variable. Due to the volume of information handled, it was not possible to include

447 the information at the variable level as explained in the method; however, the information of

448 each variable from the pre- and post-sessions (pre-value, post-value, difference, MDC, STTE,

449 PoC, CQ and the scores of each variable) of the patients' tests has been calculated and compiled 450 as supplementary material.

451

452

453

454

455

456

457

458

459

460

461

462

463

464

465

466

467

468

469

470

471

472

473

474

475

476

477

478

\section{Table 3 about here}

\section{Stage 2}

The results related to stage 2 correspond to the homogenised scores of the five tests of the 42 patients, as presented in Table 4 . This score is a discrete value between -2 and +2 ; negative values $(-2$ and -1$)$ indicate negative progression, null values $(0)$ indicate no progression and positive values ( 1 and 2 ) indicate positive progression.

\section{Stage 3}

Qualification of the scores of each patient, a process conducted in stage 3, is presented in Table 4 with the same identifying code detailed in Figure 3, where the conclusions are presented based on the scores obtained.

Table 4. Stage 2 and 3 results: homogenised scores and conclusions.

Table 4 about here

\section{Comparison between the MCQ-Balance assessment and clinician judgment}

The results of the comparison between the MCQ-Balance assessment and the assessment of clinician 3 for the RSEO and LOS tests are presented in Tables 5 and 6, respectively. They include the confusion matrix, Cohen's Kappa coefficient with its significance (p-value) and the number of false negatives.

\section{Table 5 about here}

As shown in Table 6, for the RSEO test, Cohen's Kappa coefficient is 0.752 (between $0.61-0.80$ as substantial (McHugh, 2012)), the accuracy is $83.4 \%$ between the two assessments and there are no false negatives. 
479

480

481

482

483

484

485

486

487

488

489

490

491

492

493

494

495

496

497

498

499

500

501

502

503

504

505

506

507

508

509

510

511

512

513

514

515

516

517

\section{Table 6 about here}

As shown in Table 6, for the LOS test, Cohen's Kappa coefficient is 0.581 (between $0.41-0.60$ as moderate (McHugh, 2012)), the accuracy is $72.9 \%$ between the two assessments and there are four false negatives, including three cases where the method did not detect changes and the clinical expert estimated worsening as well as one case where the method detected positive progression and the clinical expert estimated worsening.

\section{Discussion}

In this study, the MCQ-Balance assessment showed an accuracy of $83.4 \%$ compared to evaluation by an expert clinician for the detection of relevant changes in balance in patients with balance disorders. The methodology used in this study is easily reproducible, given the wide availability of the resources used.

Few studies have focused on the clinical utility of posturography at the individual patient level (Visser et al., 2008). Likewise, although posturography is considered the gold standard, limitations exist regarding its use as a functional assessment (Climent Barbera JM, 2003). Thus, MCQ-Balance assessment method proposed, focuses on the individualised monitoring of patients, try to respond to this problem. Indeed, the transformation of information from continuous quantitative variables to conclusions in medical language facilitates the clinical interpretation of the results, providing greater intelligence to posturography devices (which is a limitation detected in posturography reports) (Climent Barbera JM, 2003).

Stages two and three of the method are adapted to clinical needs because they are the result of multidisciplinary work involving clinicians and technicians. This highlights the relevance of the conclusions that the MCQ-Balance method can generate from the results of the balance tests, which have been defined and written by the clinicians involved in the present study. Likewise, the definitions of the intervals of the homogenised scores have been adjusted according to the patients that have been assessed by the clinician 2 .

The proposed method has advantages over traditional posturography; however, it is necessary to discuss certain issues and decisions related to the application process, which are explained below.

The first consideration refers to the chosen MBD threshold, a numerical value from which a change is considered relevant. Regarding this, the MDC has been selected as the reference value in the present study because it represents the random balance variability in addition to the measurement errors of the device and the experiment (Furlan, Sterr, 2018; Steffen, Seney, 2008). We choose the MDC, rather than the minimal important difference (MID), as the MBD threshold (de Vet and Terwee, 2010), consistent with previous studies (De la Torre et al., 2020).

The scoring proposed in the present work makes it possible to simplify the interpretation of the results of balance monitoring at the patient level. For this, the scoring allows the results to be 
518 standardized to enable a comparison between tests of the same patient and even between studies 519 of different patients.

520 In the present work, and according to De la Torre et al. (2017), the considered variables have the 521 same importance and are assigned the same weight. However, future studies might advise

522 assigning a different weight to each variable depending on its importance in improving the 523 sensitivity of the MCQ-Balance method for diagnostic purposes. In this case, the maximum and 524 minimum achievable score for each test would be based on the weights assigned to each variable.

525 The choice of the five intervals to establish the homogenised scores was medically motivated.

526 Clinically, it makes sense to make a five-level classification because the progression of the 527 patient is towards improvement, maintenance, or deterioration of the patient's clinical picture

528

529

530

531

532

533

534

535

536

537

538

539

540

541

542

543

544

545

546

547

548

549

550

551

552

553

554

555

556

557

(Porta, 2014), assessing the existing graduation in improvement or deterioration. The multidisciplinary agreement reached in the present work combined with the experience of fieldwork and data processing has been concluded at the presented intervals.

Regarding the conclusions in medical language resulting from the method, the ability to portray the influence of the three BSS involved in balance is highlighted in the progression of a patient's balance. In this way, the method facilitates the clinician to adapt medical treatment, focusing on the balance disorder of the patient.

MCQ-Balance assessment exceeded 70\% accuracy (relative to the assessment of clinician 3) for both the RSEO test and the LOS test, and its Cohen's Kappa coefficient was $>0.4$. Therefore, the MCQ-Balance assessment met the accuracy goals we initially established. However, the differences between the two comparisons should be highlighted. While there were no false negatives in the comparison with the RSEO test, with the LOS test, there were four $(10.8 \%$ of the sample). This is explained by the possible learning factor associated with this test (Wrisley, 2007), although 4 of the 37 patients who completed this test is not a representative sample; similar to the comparison with RSEO, there are more cases in which the method determined a negative progression (worsening) where clinician 3 did not. This may be due to the increased sensitivity of the method when detecting worsening that is not visible to the clinician with traditional assessment tools. Finally, we would like to establish that the decision to choose these two tests has been motivated because all BSSs are intact, a situation more in line with the performance of daily living activities. In our opinion is the best adaptation to the assessment of the clinician 3. Although we consider the reliability obtained in this study adequate $(>70 \%)$, delving into this type of comparison could result in further improved accuracy.

The simplicity of the MCQ-Balance assessment, as well as its portability and reproducibility, make it possible to systematize its use in the clinic as a complementary evaluation tool. However, future research should focus on verifying the viability of continued clinical use of this assessment, as well as its incorporation into the dynamics of a hospital rehabilitation service. The influence of participant characteristics has not been analysed because there is no significant difference (gender) and it is not within the scope of the research; however, it was observed that older patients showed less positive progression relative to younger patients. The analysis of the possible influences of the anthropometric variables will be addressed in a future study.

Peer) reviewing PDF | (2020:07:51331:2:1:NEW 8 Jan 2021) 
558 Regarding the progression of the patients, it can be observed that there is no trend in

559

560

561

562

563

564

565

566

567

568

569

570

571

572

573

574

575

576

577

578

579

580

581

582

583

584

585

586

587

588

589

590

591

592

593

594

595

596

597

improvement (positive progression) of the sample. The main reason lies in the nature of the prescribed treatments. To achieve effectiveness in rehabilitative treatment, patients need to be constant in performing the prescribed treatment, which is a great handicap of rehabilitation (regardless of subspecialty) (Tapias, 2014; Essery et al., 2017). Likewise, some cases of fear in the patients were detected in the post-session due to a negative experience in the pre-session. This explains certain cases that present a negative progression provided by the method. This problem is frequent in studies of balance disorders (Visser et al., 2008; Timothy C. Hain, May 5, 2019). However, we tried to minimise the problem with additional safety measures, such as the presence of the clinician 2 and a nurse around the patient during the tests.

The lack of portability of current posturography devices is problematic. More portable devices would reduce costs (given the quicker installation process and smaller space requirements) and allow the sharing of devices between different medical centres. However, the high price of more portable devices limits their accessibility and applicability (Uebbing, 2016). The reduced cost of the device used in this study, as well as its portability, supports use in lower income countries that may be unable to invest in high-cost posturography equipment.

We acknowledge the major limitation inherent to the applied treatments, although the purpose of the study was not to assess the efficacy of treatments for balance disorders. Likewise, in the assessment of those patients diagnosed with BPPV to whom the Epley manoeuvre was applied, no greater positive progression was detected than the rest of the sample due to the use of a specific treatment. The effectiveness of the treatments will be addressed in a subsequent study with a sample similar to that of the present study. Likewise, future studies should compare the MCQ-Balance assessment with the BESTest (Padgett, Jacobs \& Kasser, 2012). Besides, new output measures should be added, such as the sway directional index, sway vector (Błaszczyk, 2016), or even fractal dimension (Błaszczyk, Klonowski, 2001); as well as introduce cognitive tasks (Raymakers, Samson \& Verhaar, 2005; De la Torre, Bonnet et al., 2020). Finally, future studies should investigate the possibility of further improving the accuracy MCQ-Balance assessment by incorporating machine learning techniques.

Regarding the implications and possibilities of the assessment method MCQ-Balance, note that it is extrapolated to other cases of balance assessment with different tests, variables, and perspectives (e.g. balance during gait or by combining the test with cognitive tasks). Therefore, the conclusions transcend the present study.

\section{Conclusions}

This study assessed the accuracy and clinical utility of the MCQ-Balance assessment for measuring balance progression in patients with balance disorders. The results obtained with the MCQ-Balance assessment showed remarkable similarity to the assessment of an expert clinician, demonstrating the validity of this new method. We conclude that the proposed method provides objective information that facilitates the monitoring of patients with balance disorders and measurement of alterations in BSS.

Peer] reviewing PDF | (2020:07:51331:2:1:NEW 8 Jan 2021) 
598

599

600

601

602

603

604

605

606

607

608

609

610

611

612

613

614

615

616

617

618

619

620

621

622

623

624

625

626

627

628

629

\section{0}

631

632

633

634

635

636

637

35

\section{Abbreviations}

BPPV: Benign Paroxysmal Peripheral Vertigo

BSS: Balance Sensory System

CEICA: Research Ethics Committee of the Community of Aragon

COP: Centre Of Pressure

CQ: Quantification of the Change

CTSIB-M: Modified Clinical Test of Sensory Interaction in Balance

ES: Eye-Sight System

ICC: Intraclass Correlation Coefficient

IDERGO: Research and Development in Ergonomics

ISPGR: International Society for Posture and Gait Research

к: Cohen's Kappa Statistical Coefficient

LOS: Limits of Stability

MBD: Magnitude-Based Decision

MCQ: Measure, Classify and Qualify

MDC: Minimal Detectable Change

MID: Minimal Important Difference

PM\&R: Physical Medicine and Rehabilitation Service

PoC: Probability of Change

PS: Proprioceptive System

RSEC: Rigid Surface with Eyes Closed

RSEO: Rigid Surface with Eyes Open

SDpool: Pooled Average between the Standard Deviation of the Test and Retest

SEM: Standard Error of Measurement

SSEC: Soft Surface with Eyes Closed

SSEO: Soft Surface with Eyes Open

STTE: Short-Term Typical Error

VS: Vestibular System

Xdif: Difference Between the measures taken in two Temporal Points

\section{Acknowledgements}

We thank the I3A - University Institute of Research of Engineering of Aragon, University of Zaragoza, Zaragoza, Spain, for the materials they provided.

We also thank Alcañiz Hospital (Teruel, Spain) for allowing us to use their facilities.

\section{References}

Aftab Z, Robert T, Wieber PB. 2016. Balance Recovery Prediction with Multiple Strategies for Standing Humans. PloS one, 11:e0151166. 
638 Allum J, Zamani F, Adkin A, Ernst A. 2002. Differences between trunk sway characteristics on a 639 foam support surface and on the Equitest ${ }^{\circledR}$ ankle-sway-referenced support surface. Gait \& 640 posture, 16:264-270.

641 Ayllón FN, Fernández DF. 2006. Función y entrenamiento de la musculatura abdominal. Una 642 visión científica. Journal of Human Sport and Exercise.

643 Błaszczyk JW, Klonowski W. 2001. Postural stability and fractal dynamics. Acta Neurobiol.Exp, 644 61:105-112.

645 Bartual J, Pérez N. 1998. El sistema vestibular y sus alteraciones. Tomo, 1:21-22.

646 Baumgartner B TR. 2019 Jun 3. Peripheral Vertigo.

647 Benvenuti F, Mecacci R, Gineprari I, Bandinelli S, Benvenuti E, Ferrucci L, Baroni A, 648 Rabuffetti M, Hallett M, Dambrosia JM. 1999. Kinematic characteristics of standing 649 disequilibrium: reliability and validity of a posturographic protocol. Archives of Physical 650 Medicine and Rehabilitation, 80:278-287.

651 Błaszczyk JW. 2016. The use of force-plate posturography in the assessment of postural 652 instability. Gait \& posture, 44:1-6.

653 Boomsaad Z, Telian S, Patil P. 2017. Treatment of intractable vertigo. Youmans and Winn 654 Neurological Surgery.7th ed.Philadelphia, PA: Elsevier.

655 Cantor AB. 1996. Sample-size calculations for Cohen's kappa. Psychological methods, 1:150.

656 Charan J, Biswas T. 2013. How to calculate sample size for different study designs in medical 657 research?. Indian journal of psychological medicine, 35:121-126.

658 Choi H, Lee J. 2020. Immediate Effect of Balance Taping Using Kinesiology Tape on Dynamic 659 and Static Balance after Ankle Muscle Fatigue, 8:162.

660 Cicchetti DV. 1994. Guidelines, criteria, and rules of thumb for evaluating normed and

661 standardized assessment instruments in psychology. Psychological assessment, 6:284.

662 Climent Barbera JM. 2003. Posturografía ¿algo se mueve?. Revista de Biomecánica Instituto de 663 Biomecánica de Valencia, Febrero: 21.

664 da Costa Barbosa R, Vieira MF. 2017. Postural control of elderly adults on inclined surfaces. 665 Annals of Biomedical Engineering, 45:726-738.

666 De la Torre J, Bonnet V, Mauti R, Chabaud P, Robert T. 2020. Implementing a test to assess 667 reaction, attention and inhibition capacity in elderly. Computer methods in biomechanics and 668 biomedical engineering, 23:S294-S296.

669 De la Torre J, Marin J, Marin JJ, Auria JM, Sanchez-Valverde MB. 2017. Balance study in 670 asymptomatic subjects: Determination of significant variables and reference patterns to improve 671 clinical application. Journal of Biomechanics, 65:161-168.

672 De la Torre J, Marin J, Polo M, Marín JJ. 2020. Applying the Minimal Detectable Change of a 673 Static and Dynamic Balance Test Using a Portable Stabilometric Platform to Individually Assess 674 Patients with Balance Disorders, 8:402.

675 De Vet HC, Terwee CB. 2010. The minimal detectable change should not replace the minimal 676 important difference. Journal of clinical epidemiology, 63:804.

677 Degani AM, Leonard CT, Danna-dos-Santos A. 2017. The effects of early stages of aging on 678 postural sway: a multiple domain balance assessment using a force platform. Journal of

679 Biomechanics, 64:8-15.

680 Derebery MJ. 2000. Diagnóstico y tratamiento del vértigo. Revista Cubana de Medicina, 39:238681253.

682 Di Fabio RP. 1996. Meta-analysis of the sensitivity and specificity of platform posturography. 683 Archives of Otolaryngology-Head \& Neck Surgery, 122:150-156. 
684 Dieterich M, Eckhardt-Henn A. 2004. Neurologische und somatoforme Schwindelsyndrome. 685 Der Nervenarzt, 75:281-302.

686 Dounskaia N, Peterson D, Bruhns RP. 2018. Destabilization of the Upright Posture Through

687 Elevation of the Center of Mass. Annals of Biomedical Engineering, 46:318-323.

688 Doyle TL, Newton RU, Burnett AF. 2005. Reliability of Traditional and Fractal Dimension

689 Measures of Quiet Stance Center of Pressure in Young, Healthy People. Archives of Physical

690 Medicine and Rehabilitation, 86:2034-2040.

691 El-Kashlan HK, Shepard NT, Asher AM, Smith-Wheelock M, Telian SA. 1998. Evaluation of

692 clinical measures of equilibrium. The Laryngoscope, 108:311-319.

693 Essery R, Geraghty AW, Kirby S, Yardley L. 2017. Predictors of adherence to home-based

694 physical therapies: a systematic review. Disability and rehabilitation, 39:519-534.

695 Furlan L, Sterr A. 2018. The applicability of standard error of measurement and minimal

696 detectable change to motor learning research - a behavioral study. Frontiers in human

697 neuroscience, 12:95.

698 General Assembly of the World Medical Association. 2014. World Medical Association

699 Declaration of Helsinki: ethical principles for medical research involving human subjects. The

700 Journal of the American College of Dentists, 81:14-18.

701 González MÁM, Villegas AS, Atucha ET, Fajardo FJF. 2014. Bioestadística amigable: Elsevier

702 España.

703 Hamburg MA, Collins FS. 2010. The path to personalized medicine. New England Journal of

704 Medicine, 363:301-304.

705 Hanes DA, McCollum G. 2006. Cognitive-vestibular interactions: a review of patient difficulties

706 and possible mechanisms. Journal of Vestibular Research, 16:75-91.

707 Hansson EE, Persson L, Malmström EM. 2013. Influence of vestibular rehabilitation on neck

708 pain and cervical range of motion among patients with whiplash-associated disorder: a

709 randomized controlled trial. Journal of Rehabilitation Medicine, 45:906-910.

710 Hickey S, Ford G, Buckley J, O'connor AF. 1990. Unterberger stepping test: a useful indicator of

711 peripheral vestibular dysfunction?. The Journal of Laryngology \& Otology, 104:599-602.

712 Hopkins WG. 2017. A spreadsheet for monitoring an individual's changes and trend.

713 Sportscience, 21:10.

714 Hopkins WG. 2000. Measures of reliability in sports medicine and science. Sports medicine,

715 30:1-15.

716 Hopkins WG, Batterham AM. 2016. Error rates, decisive outcomes and publication bias with

717 several inferential methods. Sports Medicine, 46:1563-1573.

718 Hopkins WG. 2019. Rebranding MBI as magnitude-based decisions (MBD). Sportscience, 23.

719 Hoving JL, Pool JJ, van Mameren H, Devillé WJ, Assendelft WJ, de Vet HC, de Winter AF,

720 Koes BW, Bouter LM. 2005. Reproducibility of cervical range of motion in patients with neck

721 pain. BMC musculoskeletal disorders, 6:59.

722 IBM Corp. 2017. IBM SPSS Statistics for Windows, Version 25.0. Armonk, NY: IBM Corp.

723 Ito T, Sakai Y, Ito Y, Yamazaki K, Morita Y. 2020. Association Between Back Muscle Strength

724 and Proprioception or Mechanoreceptor Control Strategy in Postural Balance in Elderly Adults

725 with Lumbar Spondylosis, 8:58.

726 Jacobs JV, Horak FB, Tran VK, Nutt JG. 2006. Multiple balance tests improve the assessment of 727 postural stability in subjects with Parkinson's disease. Journal of neurology, neurosurgery, and

728 psychiatry, 77:322-326.

729 Jull GA. 2004. Grieve's modern manual therapy: the vertebral column. 
730 Karlsson A, Frykberg G. 2000. Correlations between force plate measures for assessment of

731 balance. Clinical Biomechanics, 15:365-369.

732 Khalaj N, Osman NAA, Mokhtar AH, Mehdikhani M, Abas, Wan Abu Bakar Wan. 2014.

733 Balance and risk of fall in individuals with bilateral mild and moderate knee osteoarthritis. PloS

734 one, 9.

$735 \mathrm{Ku}$ PX, Abu Osman NA, Wan Abas WAB. 2016. The limits of stability and muscle activity in

736 middle-aged adults during static and dynamic stance. Journal of Biomechanics, 49:3943-3948.

737 Lin D, Seol H, Nussbaum MA, Madigan ML. 2008. Reliability of COP-based postural sway

738 measures and age-related differences. Gait \& posture, 28:337-342.

739 López LFC, Calidonio JDL. 2009. "CgMed" Design and construction of a platform to determine

740 the position of the center of gravity in standing. Revista Ingeniería Biomédica, 3:26-36.

741 Ma CZ, Wong DW, Lam WK, Wan AH, Lee WC. 2016. Balance improvement effects of

742 biofeedback systems with state-of-the-art wearable sensors: a systematic review. Sensors,

743 16:434.

744 Martínez Carrasco Á. 2016. Análisis del riesgo de caídas en ancianos institucionalizados

745 mediante escalas de marcha y equilibrio. Proyecto de investigación:

746 Medical Subject Headings (MeSH). 2020. Vertigo MeSH Descriptor.

747 Muir JW, Kiel DP, Hannan M, Magaziner J, Rubin CT. 2013. Dynamic parameters of balance

748 which correlate to elderly persons with a history of falls. PloS one, 8:e70566.

749 Neuhauser H . 2016. The epidemiology of dizziness and vertigo Handbook of clinical neurology:

750 Elsevier, 67-82.

751 Orejas JIB, Varea JA, Rodrigo JV, Navas AC. 2020. Resultados y seguimiento de la

752 rehabilitación vestibular. Revista ORL, 11:107-114.

753 Padgett PK, Jacobs JV, Kasser SL. 2012. Is the BESTest at its best? A suggested brief version

754 based on interrater reliability, validity, internal consistency, and theoretical construct. Physical

755 Therapy, 92:1197-1207.

756 Patrícia Paludette D, Fabrício Santana da S, Carlos Bolli M. 2015. Comparação do equilíbrio

757

758

759

760

761

762

763

764

765

766

767

768

769

770

771

772

773

774 postural entre grupos de mulheres com diferentes faixas etárias / Comparison of postural balance among groups of women with different age ranges / Comparación del balance postural en un grupo de mujeres de franjas etarias distintas. Fisioterapia e Pesquisa, 22:392.

Penger M, Strobl R, Grill E. 2017. Country-specific and individual determinants of dizziness in Europe: results from the Survey of Health Ageing and Retirement in Europe (SHARE). Public health, 149:1-10.

Peterson CL, Ferrara MS, Mrazik M, Piland S, Elliott R. 2003. Evaluation of neuropsychological domain scores and postural stability following cerebral concussion in sports. Clinical Journal of Sport Medicine, 13:230-237.

Porta M. 2014. A dictionary of epidemiology: Oxford university press.

Raymakers J, Samson M, Verhaar H. 2005. The assessment of body sway and the choice of the stability parameter (s). Gait \& posture, 21:48-58.

Reiley AS, Vickory FM, Funderburg SE, Cesario RA, Clendaniel RA. 2017. How to diagnose cervicogenic dizziness. Archives of physiotherapy, 7:12.

Rubenstein LZ, Josephson KR. 2002. The epidemiology of falls and syncope. Clinics in geriatric medicine, 18:141-158.

Ruhe A, Fejer R, Walker B. 2010. The test-retest reliability of centre of pressure measures in bipedal static task conditions-a systematic review of the literature. Gait \& posture, 32:436-445.

Peer) reviewing PDF | (2020:07:51331:2:1:NEW 8 Jan 2021) 
775

776

777

778

779

780

781

782

783

784

785

786

787

788

789

790

791

792

793

794

795

796

797

798

799

800

801

802

803

804

805

806

807

808

809

810

811

812

813

814

815

816

817

818

819

Salehi R, Ebrahimi-Takamjani I, Esteki A, Maroufi N, Parnianpour M. 2010. Test-retest reliability and minimal detectable change for center of pressure measures of postural stability in elderly subjects. Medical Journal of The Islamic Republic of Iran (MJIRI), 23:224-232.

Saxena A, Prabhakar MC. 2013. Performance of DHI score as a predictor of benign paroxysmal positional vertigo in geriatric patients with dizziness/vertigo: a cross-sectional study. PloS one, 8:e58106.

Scoppa F, Capra R, Gallamini M, Shiffer R. 2013. Clinical stabilometry standardization: basic definitions-acquisition interval-sampling frequency. Gait \& posture, 37:290-292.

Shumway-Cook A, Woollacott M, Shumway-Cook A, Woollacott M. 2001. Mobility function. Motor Control: Theory and Practical Applications.Philadelphia: Lippincott Williams \& Wilkins:305-337.

Shumway-Cook A, Brauer S, Woollacott M. 2000. Predicting the probability for falls in community-dwelling older adults using the Timed Up \& Go Test. Physical Therapy, 80:896-903. Solomon D. 2000. Distinguishing and treating causes of central vertigo. Otolaryngologic clinics of North America, 33:579-601.

Stanton M FA. 2020 Apr 28. Vertigo.

Steffen T, Seney M. 2008. Test-retest reliability and minimal detectable change on balance and ambulation tests, the 36-item short-form health survey, and the unified Parkinson disease rating scale in people with parkinsonism. Physical Therapy, 88:733-746.

Stewart MG, Chen AY, Wyatt JR, Favrot S, Beinart S, Coker NJ, Jenkins HA. 1999.

Cost-effectiveness of the diagnostic evaluation of vertigo. The Laryngoscope, 109:600-605.

Strupp M, Dieterich M, Brandt T. 2013. The treatment and natural course of peripheral and central vertigo. Deutsches Ärzteblatt International, 110:505.

Swanenburg J, de Bruin ED, Favero K, Uebelhart D, Mulder T. 2008. The reliability of postural balance measures in single and dual tasking in elderly fallers and non-fallers. $B M C$

musculoskeletal disorders, 9:162.

Swanenburg J, de Bruin ED, Stauffacher M, Mulder T, Uebelhart D. 2007. Effects of exercise and nutrition on postural balance and risk of falling in elderly people with decreased bone mineral density: randomized controlled trial pilot study. Clinical rehabilitation, 21:523-534.

Tapias LM. 2014. Factores individuales que influyen en la adherencia al tratamiento fisioterapéutico. Una revisión del tema.(Determining individual aspects treatment adherence in population with disabilities in Medellin city: a literature review). CES Movimiento y Salud, 2:2330.

Taylor MR, Sutton EE, Diestelkamp WS, Bigelow KE. 2015. Subtle differences during posturography testing can influence postural sway results: The effects of talking, time before data acquisition, and visual fixation. Journal of applied biomechanics, 31:324-329.

Tesio L, Rota V, Longo S, Grzeda MT. 2013. Measuring standing balance in adults: reliability and minimal real difference of 14 instrumental measures. International journal of rehabilitation research, 36:362-374.

Timothy C. Hain M. May 5, 2019. MOVING PLATFORM POSTUROGRAPHY TESTING Computerized Dynamic Posturography (CDP).

Tinetti ME. 2003. Preventing falls in elderly persons. New England journal of medicine, 348:4249.

Tsukamoto HF, Costa, Viviane de Souza Pinho, Silva Junior, Rubens Alexandre da, Pelosi GG, Marchiori, Luciana Lozza de Moraes, Vaz CRS, Fernandes KBP. 2015. Effectiveness of a

Peer) reviewing PDF | (2020:07:51331:2:1:NEW 8 Jan 2021) 
820 vestibular rehabilitation protocol to improve the health-related quality of life and postural

821 balance in patients with vertigo. International archives of otorhinolaryngology, 19:238-247.

822 Uebbing TJ. 2016. User experience in smart environments: design and prototyping.

823 Vaupel JW, Loichinger E. 2006. Redistributing work in aging Europe. Science (New York, N.Y.),

824 312:1911-1913.

825 Vellas BJ, Wayne SJ, Romero L, Baumgartner RN, Rubenstein LZ, Garry PJ. 1997. One-leg

826 balance is an important predictor of injurious falls in older persons. Journal of the American

827 Geriatrics Society, 45:735-738.

828 Visser JE, Carpenter MG, van der Kooij H, Bloem BR. 2008. The clinical utility of

829 posturography. Clinical Neurophysiology, 119:2424-2436.

830 Von Lubitz D, Wickramasinghe N. 2006. Healthcare and technology: the doctrine of

831 networkcentric healthcare. International Journal of Electronic Healthcare, 2:322-344.

832 Wipperman J. 2014. Dizziness and vertigo. Primary Care: Clinics in Office Practice, 41:115-

833131.

834 Wolf SL, Barnhart HX, Kutner NG, McNeely E, Coogler C, Xu T, Atlanta FICSIT Group. 1996.

835 Reducing frailty and falls in older persons: an investigation of Tai Chi and computerized balance

836 training. Journal of the American Geriatrics Society, 44:489-497.

837 Wrisley D. 2007. Vision of balance rehabilitation. a Paradigm Shift: Technology based

838 intervention improving outcomes for dysequilibrium, dizziness, mobility, balance, and falls,

839 Celebration, Florida, USA.

840 Yin M, Ishikawa K, Wong WH, Shibata Y. 2009. A clinical epidemiological study in 2169

841 patients with vertigo. Auris Nasus Larynx, 36:30-35.

842 


\section{Figure 1}

Stabilometric platform and test work environment.

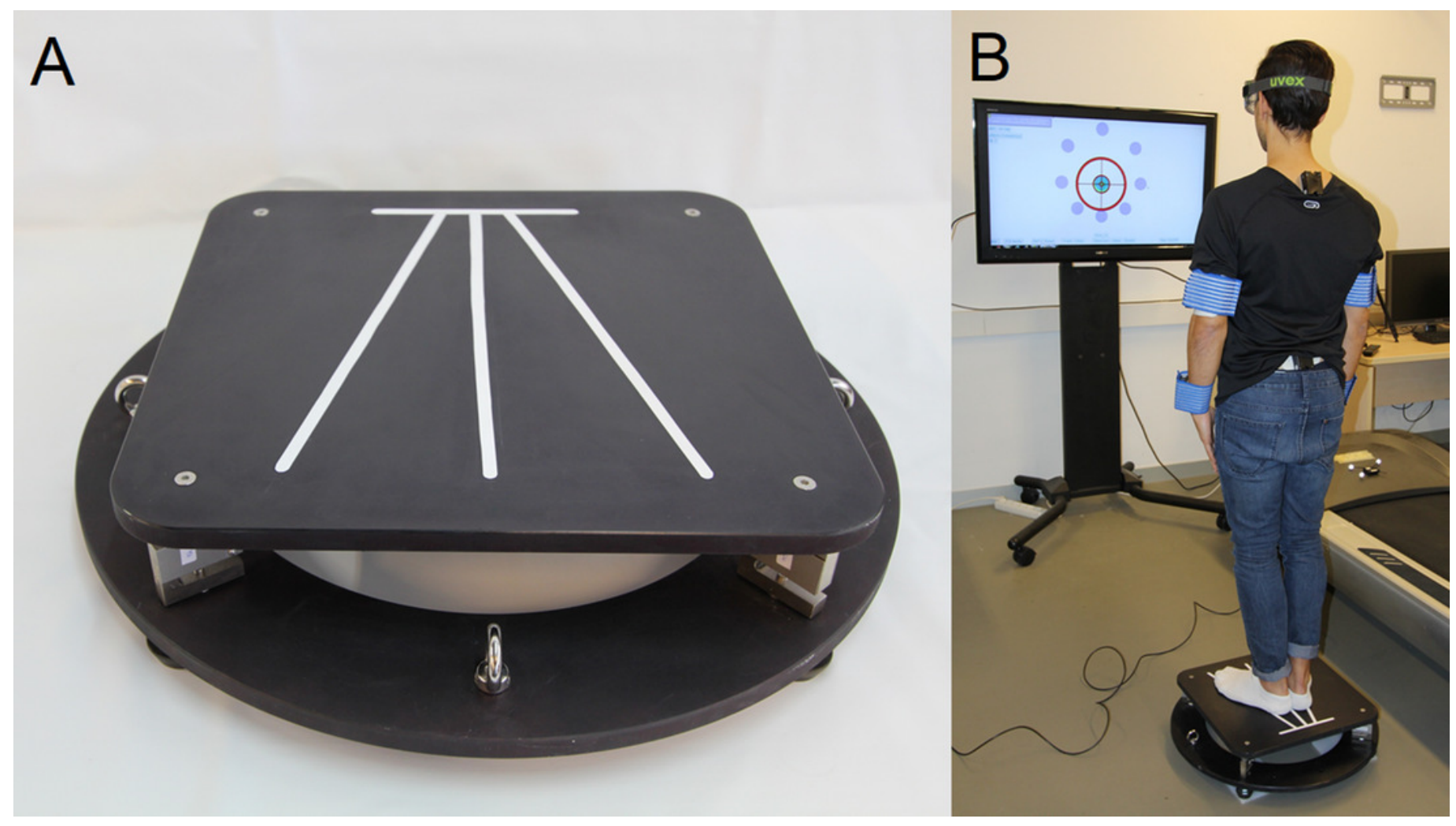


Figure 2

MCQ-Balance assessment method: processes, inputs, outputs from the different stages.

MCQ-BALANCE ASSESSMENT METHOD OF BALANCE PROGRESSION

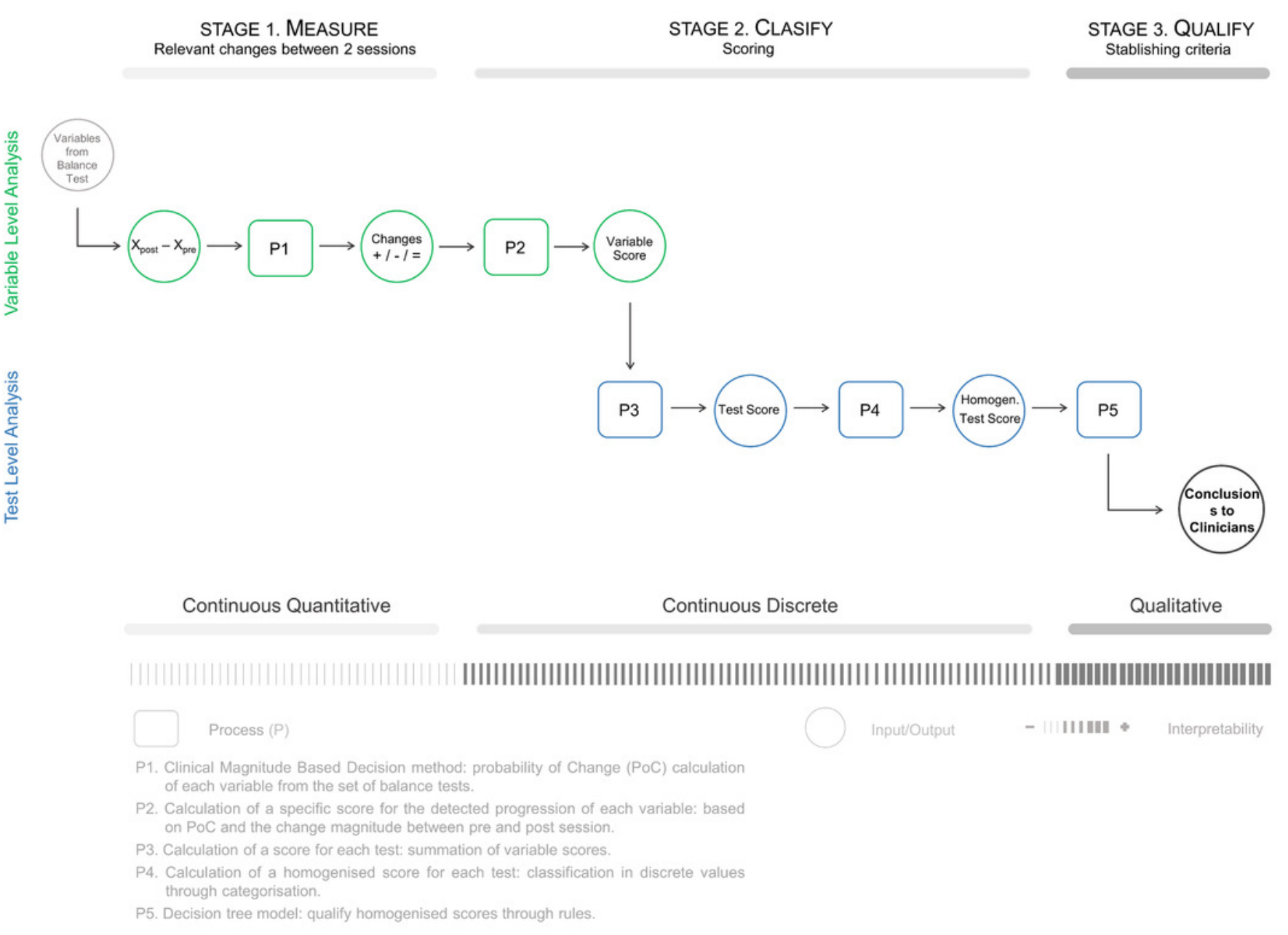




\section{Figure 3}

Rules to qualify the balance progression of a patient and the influence of the balance sensory systems.

RSEO: Rigid Surface, Eyes Open; RSEC: Rigid Surface, Eyes Closed; SSEO: Soft Surface, Eyes Open; SSEC: Rigid Surface, Eyes Closed. VS: vestibular system; ES: visual system; PS:

proprioceptive system. E1,..., E3: conclusions for the progression of static balance; D1,.., D3: conclusions for the progression of dynamic postural balance; V1,..., V3: conclusions for the progression of balance due to VS; S1,... S9: conclusions for the progression of balance due to ES; P1,.., P9: conclusions for the progression of balance due to PS. 


\section{RULES TO QUALIFY THE BALANCE PROGRESSION OF A PATIENT AND THE INFLUENCE OF THE SENSORY SYSTEMS}

\section{Rules of direct obtaining}

Rule 1. Overall progression of Static balance

$$
\mathrm{RSEO}=0 \quad-\mathrm{S} 1
$$

RSEO $=+1 /+2-S 2$

RSEO $=-1 /-2-S 3$
Rule 2. Overall progression of Dynamic balance

$$
\begin{gathered}
\text { LOS }=0-D 1 \\
\text { LOS }=+1 /+2-D 2 \\
\text { LOS }=-1 /-2-D 3
\end{gathered}
$$

Rule 3. Progression of balance due to Vestibular system

SSEC $=0 \quad-\mathrm{v} 1$

SSEC $=+1 /+2-V 2$

SSEC $=-1 /-2-V 3$

\section{Rules of obtaining by combination}

Rule 4. Progression of balance due to Eyesight system

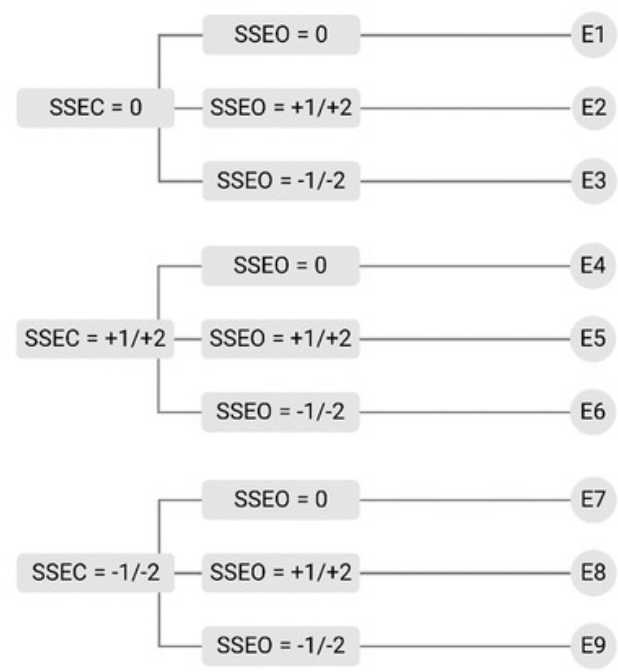

Rule 5. Progression of balance due to Proprioceptive system

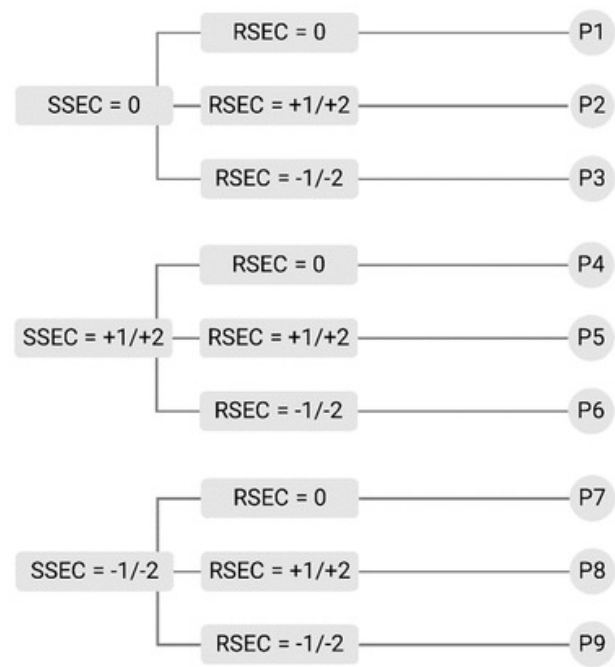

\section{Conclusions for each situation assessed}

_ S1: No progression in the overall static balance.

S2: Positive progression in the overall static balance.

$\underset{\sim}{ }$ s3: Negative progression in the overall static balance.

D1: No progression in the dynamic postural balance.

을 D2: Positive progression in the dynamic postural balance.

$\underset{\sim}{ }$ D3: Negative progression in the dynamic postural balance.

m V1: No progression in the balance due to the VS

D V2: Positive balance progression due to the VS.

$\underset{\sim}{ }$ V3: Negative balance progression due to the VS.

E1: With the PS altered, without demonstrable changes in the VS: no balance progression due to the ES are demonstrated.

E2: With the PS altered, without demonstrable changes in the VS: positive balance progression is due to the ES.

- E3: With the PS altered, without demonstrable changes in the VS: negative

o balance progression is due to the ES.

줄 With the PS altered, the improvement of the VS is compensated for by the deficit of the ES: negative balance progression due to the ES.

E5: With the PS altered, considering the improvement of the VS: no balance progression are demonstrated due to the ES.

E6: With the PS altered, the improvement of the VS is compensated for by the significant deficit of the ES: very negative balance progression is due to the ES.
E7: With the PS altered, the deterioration of the VS is compensated for by the improvement of the ES: positive balance progression due to the ES.

E8: With the PS altered, the deterioration of the VS is compensated for by the significant improvement of the ES: very positive balance progression is due to the ES.

E9: With the PS altered, considering the deterioration of the VS: no balance progression are demonstrated due to the ES

P1: With the ES altered, without demonstrable changes in the VS: no balance progression due to the PS are demonstrated.

P2: With the ES altered, without demonstrable changes in the VS: positive balance progression is due to the PS.

P3: With the ES altered, without demonstrable changes in the vestibular system: negative balance progression is due to the PS.

P4: With the ES altered, the improvement of the VS is compensated for by the deficit of the PS: negative balance progression is due to the PS.

Ð P5: With the ES altered, considering the improvement of the VS: no balance $\widetilde{\sim}$ progression are demonstrated due to the PS.

P6: With the ES altered, the improvement of the VS is compensated for by the significant deficit of the PS: very negative balance progression is due to the PS. P7: With the ES altered, the deterioration of the VS is compensated for by the improvement of the PS: positive balance progression is due to the PS.

P8: With the ES altered, the deterioration of the VS is compensated for by the significant improvement of the PS: very positive balance progression is due to the PS P9: With the ES altered, considering the deterioration of the VS: no balance progression are demonstrated due to the PS. 


\section{Table 1 (on next page)}

Patients diagnosis according to their deficits.

BPPV: benign paroxysmal peripheral vertigo 
1 Table 1:

2 Patients diagnosis according to their deficits.

3 BPPV: benign paroxysmal peripheral vertigo

\begin{tabular}{cc}
\hline \hline Peripherical deficit $\mathbf{n}=\mathbf{3 2} \mathbf{( 7 6 . 2 \% )}$ & Central deficit $\mathbf{n = 1 0}(\mathbf{2 3 . 8 \%})$ \\
\hline \hline BPPB $n=15(36 \%)$ & Ictus $n=6(14 \%)$ \\
Ménière syndrome $n=8(19 \%)$ & Neoplasia $n=2(5 \%)$ \\
Vestibular hypofunction $n=6(14 \%)$ & Demyelinating disease $n=2(5 \%)$ \\
Otoesclerosis $n=3(7 \%)$ & \\
\hline \hline
\end{tabular}




\section{Table 2 (on next page)}

Participant anthropometric characteristics: mean (SD).

${ }^{\mathrm{a}}$ Foot length measurements were taken between the proximal and distal points on the foot outline (Pawar \& Dadhich, 2012). 
1 Table 2:

2 Participant anthropometric characteristics: mean (SD).

3 a Foot length measurement was taken between the proximal and distal points on the foot outline 4 (Pawar, Dadhich, 2012).

5

\begin{tabular}{cc}
\hline \hline Characteristics & Patients (n=42) \\
\hline \hline Gender (men/women) & $15 / 27$ \\
Age (yr) & $57.1(8.7)$ \\
Height (cm) & $162.8(7.9)$ \\
Weight (kg) & $76.5(15.8)$ \\
Body Mass Index (kg/m $\mathbf{m}^{\mathbf{2}}$ & $28.7(5.6)$ \\
Foot length (cm) & $25.3(1.1)$ \\
Abdominal perimeter (cm) & $97.1(14.9)$ \\
Deficit (Peripherical / Central) & $32 / 10$ \\
\hline \hline
\end{tabular}

6 


\section{Table 3 (on next page)}

Stage 1 results: Probability of change of each patient and test.

ID: patient identifier; Def: vertigo deficit; P: peripherical deficit; C: central deficit; n/a: test not performed; RSEO: rigid surface eyes open; RSEC: rigid surface eyes closed; SSEO: soft surface eyes open; SSEC: soft surface eyes closed; LOS: limits of stability. 


\section{Table 3:}

2 Stage 1 results: Probability of change of each patient and test.

3 ID: patient identifier; Def: vertigo deficit; P: peripherical deficit; C: central deficit; n/a: test not 4 performed; RSEO: rigid surface eyes open; RSEC: rigid surface eyes closed; SSEO: soft surface 5 eyes open; SSEC: soft surface eyes closed; LOS: limits of stability.

\begin{tabular}{ccccccc|ccccccc}
\hline \hline ID & Def & RSEO & RSEC & SSEO & SSEC & LOS & ID & Def & RSEO & RSEC & SSEO & SSEC & LOS \\
\hline $\mathbf{0 1}$ & $\mathrm{P}$ & 0.12 & 0.79 & 0.16 & 0.40 & 0.11 & $\mathbf{2 2}$ & $\mathrm{P}$ & 0.22 & 0.29 & 0.26 & 0.70 & 0.72 \\
$\mathbf{0 2}$ & $\mathrm{P}$ & -0.06 & -0.12 & -0.17 & -0.38 & -0.08 & $\mathbf{2 3}$ & $\mathrm{P}$ & 0.58 & 0.02 & 0.06 & 0.35 & 0.16 \\
$\mathbf{0 3}$ & $\mathrm{P}$ & 0.19 & -0.03 & 0.15 & -0.05 & 0.09 & $\mathbf{2 4}$ & $\mathrm{C}$ & 0.09 & 0.77 & 0.69 & -0.74 & 0.01 \\
$\mathbf{0 4}$ & $\mathrm{P}$ & -0.21 & -0.80 & -1.00 & -0.52 & -0.23 & $\mathbf{2 5}$ & $\mathrm{P}$ & -0.30 & -0.40 & -0.60 & -0.37 & 0.05 \\
$\mathbf{0 5}$ & $\mathrm{P}$ & -0.49 & -0.49 & -0.30 & 0.06 & -0.10 & $\mathbf{2 6}$ & $\mathrm{C}$ & 0.21 & -0.06 & -0.06 & 0.22 & 0.19 \\
$\mathbf{0 6}$ & $\mathrm{P}$ & -0.14 & -0.26 & 0.02 & -0.62 & -0.14 & $\mathbf{2 7}$ & $\mathrm{P}$ & -0.15 & -0.39 & 0.48 & -0.31 & -0.15 \\
$\mathbf{0 7}$ & $\mathrm{P}$ & 0.39 & -0.02 & 0.46 & 0.18 & 0.34 & $\mathbf{2 8}$ & $\mathrm{P}$ & 0.00 & -0.19 & -0.03 & 0.35 & -0.07 \\
$\mathbf{0 8}$ & $\mathrm{P}$ & 0.13 & -0.31 & 0.21 & -0.22 & 0.15 & $\mathbf{2 9}$ & $\mathrm{P}$ & 0.18 & 1.00 & 0.58 & 0.23 & -0.07 \\
$\mathbf{0 9}$ & $\mathrm{P}$ & -0.66 & -0.02 & 0.15 & -0.46 & 0.13 & $\mathbf{3 0}$ & $\mathrm{C}$ & 0.62 & 0.40 & 0.76 & 0.26 & -0.21 \\
$\mathbf{1 0}$ & $\mathrm{P}$ & -0.57 & -0.02 & 0.15 & -0.93 & 0.15 & $\mathbf{3 1}$ & $\mathrm{P}$ & 0.05 & -0.15 & -0.34 & -0.13 & 0.06 \\
$\mathbf{1 1}$ & $\mathrm{P}$ & -0.05 & -0.05 & -0.03 & 0.04 & -0.07 & $\mathbf{3 2}$ & $\mathrm{P}$ & -0.78 & 0.09 & -0.23 & -0.94 & -0.32 \\
$\mathbf{1 2}$ & $\mathrm{P}$ & -1.00 & $\mathrm{n} / \mathrm{a}$ & $\mathrm{n} / \mathrm{a}$ & $\mathrm{n} / \mathrm{a}$ & $\mathrm{n} / \mathrm{a}$ & $\mathbf{3 3}$ & $\mathrm{P}$ & -0.04 & -0.73 & 0.19 & -0.06 & 0.00 \\
$\mathbf{1 3}$ & $\mathrm{P}$ & 0.25 & -0.06 & -0.39 & -0.52 & 0.16 & $\mathbf{3 4}$ & $\mathrm{C}$ & -0.80 & -0.69 & 0.28 & $\mathrm{n} / \mathrm{a}$ & $\mathrm{n} / \mathrm{a}$ \\
$\mathbf{1 4}$ & $\mathrm{C}$ & -1.00 & -0.98 & $\mathrm{n} / \mathrm{a}$ & $\mathrm{n} / \mathrm{a}$ & $\mathrm{n} / \mathrm{a}$ & $\mathbf{3 5}$ & $\mathrm{P}$ & 0.23 & -0.19 & 0.26 & 0.18 & 0.17 \\
$\mathbf{1 5}$ & $\mathrm{P}$ & -0.14 & -0.64 & -0.90 & 0.98 & -0.05 & $\mathbf{3 6}$ & $\mathrm{P}$ & 0.10 & -0.43 & 0.22 & -0.14 & -0.16 \\
$\mathbf{1 6}$ & $\mathrm{P}$ & 0.19 & 0.94 & 0.59 & 0.99 & 0.16 & $\mathbf{3 7}$ & $\mathrm{P}$ & 0.13 & 1.00 & -0.03 & 0.29 & 0.16 \\
$\mathbf{1 7}$ & $\mathrm{C}$ & 0.17 & 0.00 & -0.07 & 0.75 & 0.43 & $\mathbf{3 8}$ & $\mathrm{C}$ & -0.86 & -0.32 & 0.07 & -0.71 & 0.00 \\
$\mathbf{1 8}$ & $\mathrm{P}$ & -0.07 & -0.30 & 0.84 & -0.26 & 0.13 & $\mathbf{3 9}$ & $\mathrm{P}$ & 0.15 & 0.55 & -0.06 & -0.08 & 0.17 \\
$\mathbf{1 9}$ & $\mathrm{P}$ & -0.40 & -0.25 & 0.50 & 0.04 & -0.26 & $\mathbf{4 0}$ & $\mathrm{C}$ & -1.00 & $\mathrm{n} / \mathrm{a}$ & $\mathrm{n} / \mathrm{a}$ & $\mathrm{n} / \mathrm{a}$ & $\mathrm{n} / \mathrm{a}$ \\
$\mathbf{2 0}$ & $\mathrm{C}$ & -0.20 & -0.22 & -0.64 & -0.43 & 0.58 & $\mathbf{4 1}$ & $\mathrm{C}$ & -0.68 & -0.63 & -0.84 & $\mathrm{n} / \mathrm{a}$ & $\mathrm{n} / \mathrm{a}$ \\
$\mathbf{2 1}$ & $\mathrm{P}$ & 0.07 & 0.05 & -0.38 & -0.08 & 0.11 & $\mathbf{4 2}$ & $\mathrm{P}$ & -0.19 & -0.11 & -0.11 & -0.03 & 0.01 \\
\hline \hline
\end{tabular}




\section{Table 4 (on next page)}

Stage 2 results - homogenised scores - and stage 3 results - conclusions - of each patient.

ID: patient identifier; Def: vertigo deficit; P: peripherical deficit; C: central deficit; n/a: tests not performed; RSEO: rigid surface eyes open; RSEC: rigid surface eyes closed; SSEO: soft surface eyes open; SSEC: soft surface eyes closed; LOS: limits of stability; R1...R5: Rules from stage 3 , consult figure $3 ; S, D, V, P, E$ : consult conclusions from figure 3. 


\section{Table 4:}

2 Stage 2 results - homogenised scores - and stage 3 results - conclusions - of each patient.

3 ID: patient identifier; Def: vertigo deficit; P: peripherical deficit; C: central deficit; n/a: tests not 4 performed; RSEO: rigid surface eyes open; RSEC: rigid surface eyes closed; SSEO: soft surface 5 eyes open; SSEC: soft surface eyes closed; LOS: limits of stability; R1...R5: Rules from stage 3, 6 consult figure $3 ; \mathrm{S}, \mathrm{D}, \mathrm{V}, \mathrm{P}, \mathrm{E}$ : consult conclusions from figure 3.

\begin{tabular}{|c|c|c|c|c|c|c|c|c|c|c|c|c|}
\hline \multirow[b]{2}{*}{ ID } & \multirow[b]{2}{*}{ VO } & \multirow[b]{2}{*}{ CA } & \multicolumn{5}{|c|}{ STAGE 2: CLASIFY } & \multicolumn{5}{|c|}{ STAGE 3: QUALIFY } \\
\hline & & & RSEO & RSEC & SSEO & SSEC & LOS & R1 & $\mathbf{R 2}$ & R3 & R4 & R5 \\
\hline 01 & $P$ & $=$ & 0 & 2 & 0 & 1 & 0 & S1 & D1 & V2 & E4 & P5 \\
\hline 02 & $\mathrm{P}$ & $=$ & 0 & 0 & -1 & -1 & 0 & $\mathrm{~S} 1$ & D1 & V3 & E9 & P7 \\
\hline 03 & $\mathrm{P}$ & + & 1 & 0 & 0 & 0 & 1 & $\mathrm{~S} 2$ & D2 & V1 & E1 & P1 \\
\hline 04 & $\mathrm{P}$ & - & -1 & -2 & -2 & -2 & -1 & S3 & D3 & V3 & E9 & P9 \\
\hline 05 & $\mathrm{P}$ & - & -2 & -2 & -1 & 0 & -1 & S3 & D3 & V1 & E3 & P3 \\
\hline 06 & $\mathrm{P}$ & $=$ & -1 & -1 & 0 & -2 & 0 & S3 & D1 & V3 & E7 & P9 \\
\hline 07 & $\mathrm{P}$ & + & 2 & 0 & 2 & 1 & 1 & $\mathrm{~S} 2$ & D2 & V2 & E5 & P4 \\
\hline 08 & $\mathrm{P}$ & $=$ & 0 & -2 & 1 & -1 & 0 & $\mathrm{~S} 1$ & D1 & V3 & E8 & P9 \\
\hline 09 & $\mathrm{P}$ & + & -2 & 0 & 1 & -1 & 1 & S3 & D2 & V3 & E8 & P7 \\
\hline 10 & $\mathrm{P}$ & - & -2 & 0 & 1 & -2 & 0 & S3 & D1 & V3 & E8 & P7 \\
\hline 11 & $\mathrm{P}$ & + & 0 & 0 & 0 & 0 & 0 & S1 & D1 & V1 & E1 & $\mathrm{P} 1$ \\
\hline 12 & $\mathrm{P}$ & - & -2 & $\mathrm{n} / \mathrm{a}$ & $\mathrm{n} / \mathrm{a}$ & $\mathrm{n} / \mathrm{a}$ & $\mathrm{n} / \mathrm{a}$ & S3 & $\mathrm{n} / \mathrm{a}$ & $\mathrm{n} / \mathrm{a}$ & $\mathrm{n} / \mathrm{a}$ & $\mathrm{n} / \mathrm{a}$ \\
\hline 13 & $\mathrm{P}$ & + & 1 & 0 & -1 & -2 & 1 & S2 & D2 & V3 & E9 & P7 \\
\hline 14 & $\mathrm{C}$ & - & -2 & -2 & $\mathrm{n} / \mathrm{a}$ & $\mathrm{n} / \mathrm{a}$ & $\mathrm{n} / \mathrm{a}$ & S3 & $\mathrm{n} / \mathrm{a}$ & $\mathrm{n} / \mathrm{a}$ & $\mathrm{n} / \mathrm{a}$ & $\mathrm{n} / \mathrm{a}$ \\
\hline 15 & $\mathrm{P}$ & + & -1 & -2 & -2 & 2 & 0 & S3 & D1 & V2 & E6 & P6 \\
\hline 16 & $\mathrm{P}$ & + & 1 & 2 & 2 & 2 & 1 & $\mathrm{~S} 2$ & D2 & V2 & E5 & P5 \\
\hline 17 & $\mathrm{C}$ & + & 1 & 0 & 0 & 2 & 1 & $\mathrm{~S} 2$ & D2 & V2 & E4 & P4 \\
\hline 18 & $\mathrm{P}$ & $=$ & 0 & -1 & 2 & -1 & 0 & $\mathrm{~S} 1$ & D1 & V3 & E8 & P9 \\
\hline 19 & $\mathrm{P}$ & $=$ & -2 & -1 & 2 & 0 & -1 & S3 & D3 & V1 & E2 & P3 \\
\hline 20 & $\mathrm{C}$ & - & -1 & -1 & -2 & -1 & 2 & S3 & D2 & V3 & E9 & P9 \\
\hline 21 & $P$ & $=$ & 0 & 0 & -1 & 0 & 0 & $\mathrm{~S} 1$ & D1 & V1 & E3 & P1 \\
\hline 22 & $\mathrm{P}$ & + & 1 & 1 & 1 & 2 & 2 & $\mathrm{~S} 2$ & D2 & V2 & E5 & P5 \\
\hline 23 & $\mathrm{P}$ & + & 2 & 0 & 0 & 1 & 1 & S2 & D2 & V2 & E4 & P4 \\
\hline 24 & $\mathrm{C}$ & $=$ & 0 & 2 & 2 & -2 & 0 & S1 & D1 & V3 & E8 & P8 \\
\hline 25 & $\mathrm{P}$ & - & -1 & -2 & -2 & -1 & 0 & S3 & D1 & V3 & E9 & P9 \\
\hline 26 & $\mathrm{C}$ & + & 1 & 0 & 0 & 1 & 1 & S2 & D2 & V2 & E4 & P4 \\
\hline 27 & $\mathrm{P}$ & - & -1 & -1 & 2 & -1 & -1 & S3 & D3 & V3 & E8 & P9 \\
\hline 28 & $\mathrm{P}$ & $=$ & 0 & -1 & 0 & 1 & 0 & $\mathrm{~S} 1$ & D1 & V2 & E4 & P6 \\
\hline 29 & $P$ & + & 1 & 2 & 2 & 1 & 0 & $\mathrm{~S} 2$ & D1 & V2 & E5 & P5 \\
\hline 30 & C & + & 2 & 1 & 2 & 1 & -1 & S2 & D3 & V2 & E5 & P5 \\
\hline 31 & $\mathrm{P}$ & $=$ & 0 & 0 & -1 & 0 & 0 & $\mathrm{~S} 1$ & D1 & V1 & E3 & P1 \\
\hline 32 & $\mathrm{P}$ & - & -2 & 0 & -1 & -2 & -1 & S3 & D3 & V3 & E9 & P7 \\
\hline 33 & $\mathrm{P}$ & $=$ & 0 & -2 & 1 & 0 & 0 & S1 & D1 & V1 & E2 & P3 \\
\hline 34 & C & - & -2 & -2 & 1 & $\mathrm{n} / \mathrm{a}$ & $\mathrm{n} / \mathrm{a}$ & S3 & $\mathrm{n} / \mathrm{a}$ & $\mathrm{n} / \mathrm{a}$ & $\mathrm{n} / \mathrm{a}$ & $\mathrm{n} / \mathrm{a}$ \\
\hline 35 & $\mathrm{P}$ & + & 1 & -1 & 1 & 1 & 1 & $\mathrm{~S} 2$ & D2 & V2 & E5 & P6 \\
\hline 36 & $\mathrm{P}$ & $=$ & 0 & -2 & 1 & -1 & -1 & $\mathrm{~S} 1$ & D3 & V3 & E8 & P9 \\
\hline 37 & $\mathrm{P}$ & + & 1 & 2 & 0 & 1 & 1 & $\mathrm{~S} 2$ & D2 & V2 & E4 & P5 \\
\hline 38 & C & - & -2 & -1 & 0 & -2 & 0 & S3 & D1 & V3 & E7 & P9 \\
\hline 39 & $\mathrm{P}$ & + & 1 & 2 & 0 & 0 & 0 & $\mathrm{~S} 2$ & D1 & V1 & E1 & $\mathrm{P} 2$ \\
\hline 40 & $\mathrm{C}$ & - & -2 & $\mathrm{n} / \mathrm{a}$ & $\mathrm{n} / \mathrm{a}$ & $\mathrm{n} / \mathrm{a}$ & $\mathrm{n} / \mathrm{a}$ & S3 & $\mathrm{n} / \mathrm{a}$ & $\mathrm{n} / \mathrm{a}$ & $\mathrm{n} / \mathrm{a}$ & $\mathrm{n} / \mathrm{a}$ \\
\hline 41 & $\mathrm{C}$ & $=$ & -2 & -2 & -2 & $\mathrm{n} / \mathrm{a}$ & $\mathrm{n} / \mathrm{a}$ & S3 & $\mathrm{n} / \mathrm{a}$ & $\mathrm{n} / \mathrm{a}$ & $\mathrm{n} / \mathrm{a}$ & $\mathrm{n} / \mathrm{a}$ \\
\hline 42 & $\mathrm{P}$ & + & -1 & 0 & 0 & 0 & 0 & S3 & D1 & V1 & E1 & $\mathrm{P} 1$ \\
\hline
\end{tabular}




\section{Table 5 (on next page)}

MCQ-Balance assessment and clinician judgment comparative: rigid surface eyes open test.

N: count of each case; \%: percentage of total. 
1 Table 5:

2 MCQ-Balance assessment and clinician judgment comparative: rigid surface eyes open test.

$3 \mathrm{~N}$ : count of each case; \%: percentage of total.

4

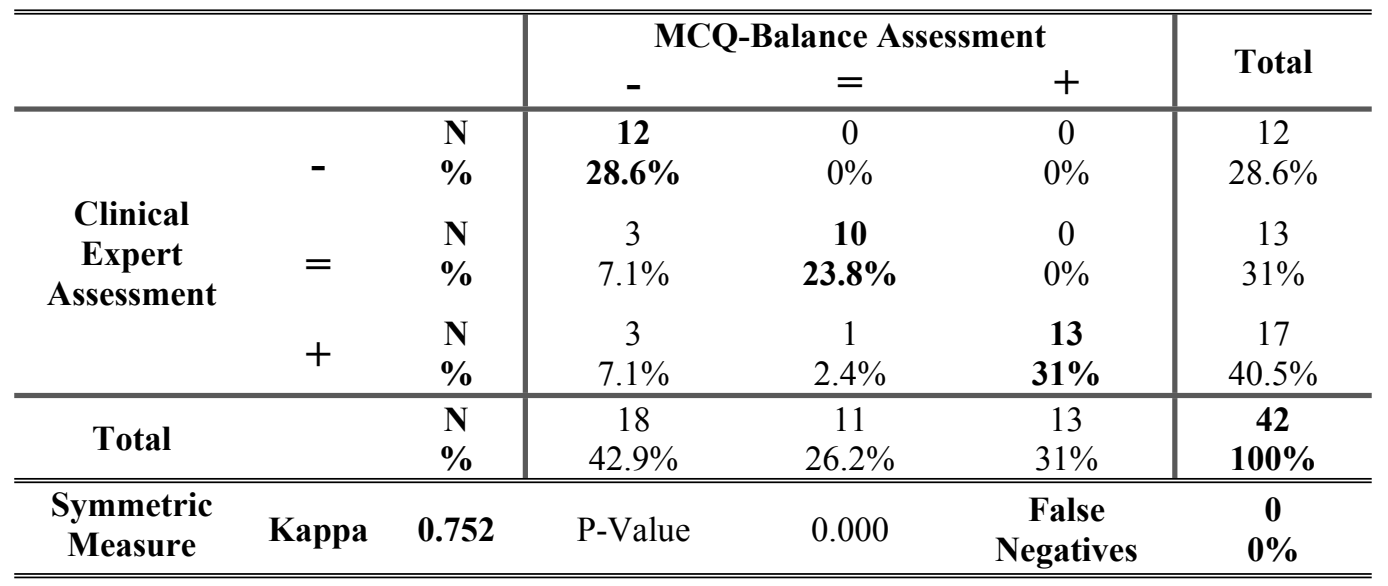




\section{Table 6(on next page)}

MCQ-Balance assessment and clinician judgment comparative: limits of stability test.

$\mathrm{N}$ : count of each case; \%: percentage of total. 
1 Table 6:

2 MCQ-Balance assessment and clinician judgment comparative: limits of stability test.

$3 \mathrm{~N}$ : count of each case; \%: percentage of total.

4

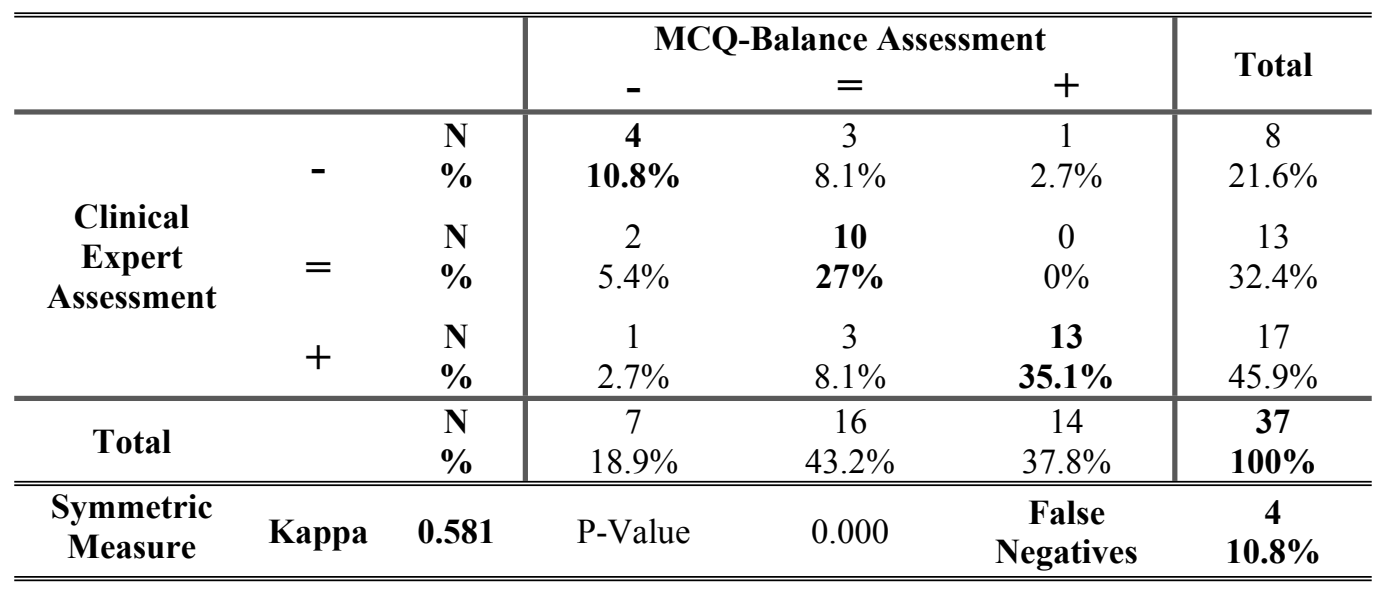

